\title{
Superior oxidation and spallation resistant NiCoCrAIY bond coat via homogenizing the yttrium distribution
}

DOI:

10.1016/j.corsci.2019.108145

\section{Document Version}

Accepted author manuscript

Link to publication record in Manchester Research Explorer

\section{Citation for published version (APA):}

Lu, J., Chen, Y., Zhang, H., Zhao, C., Zhao, X., Guo, F., \& Xiao, P. (2019). Superior oxidation and spallation resistant NiCoCrAlY bond coat via homogenizing the yttrium distribution. Corrosion Science.

https://doi.org/10.1016/j.corsci.2019.108145

\section{Published in:}

Corrosion Science

\section{Citing this paper}

Please note that where the full-text provided on Manchester Research Explorer is the Author Accepted Manuscript or Proof version this may differ from the final Published version. If citing, it is advised that you check and use the publisher's definitive version.

\section{General rights}

Copyright and moral rights for the publications made accessible in the Research Explorer are retained by the authors and/or other copyright owners and it is a condition of accessing publications that users recognise and abide by the legal requirements associated with these rights.

\section{Takedown policy}

If you believe that this document breaches copyright please refer to the University of Manchester's Takedown Procedures [http://man.ac.uk/04Y6Bo] or contact uml.scholarlycommunications@manchester.ac.uk providing relevant details, so we can investigate your claim.

\section{OPEN ACCESS}




\title{
Superior oxidation and spallation resistant NiCoCrAIY bond coat via homogenizing the yttrium distribution
}

Jie Lu ${ }^{a}$, Ying Chen ${ }^{b}$, Chunshan Zhao ${ }^{a}$, Xiaofeng Zhao ${ }^{a, *}$, Fangwei Guo ${ }^{a}$, Ping Xiao $c$

${ }^{a}$ Shanghai Key Laboratory of Advanced High-Temperature Materials and Precision Forming, School of Materials Science and Engineering, Shanghai Jiao Tong University, Shanghai, 200240, China

${ }^{b}$ OxMet Technologies, Begbroke Science Park, Oxford shire, OX5 1PF, United Kingdom

${ }^{c}$ School of Materials, The University of Manchester, MSS Tower, Manchester M13 9PL, United Kingdom

\begin{abstract}
We present a novel approach to significantly improve the oxidation and spallation resistance of a NiCoCrAlY bond coat by homogenizing the yttrium distribution via powder milling and subsequent spark plasma sintering. The NiCoCrAlY bond coat fabricated by this method exhibits a much lower oxidation rate and a significantly better spallation resistance after isothermal oxidation at $1150{ }^{\circ} \mathrm{C}$, compared with the counterpart fabricated from the un-milled powder. To understand the improvement in oxidation resistance, the microstructure of the bond coats, the chemistry and microstructure of the thermally grown oxides (TGOs), the TGO stresses and the interfacial chemistry are systemically investigated.
\end{abstract}

Keywords: NiCoCrAlY; Yttrium distribution; Oxidation; Spallation; Lifetime;

\footnotetext{
${ }^{*}$ Corresponding author: Xiaofeng Zhao

Tel./fax:+86-21-54742561.

(xiaofengzhao@sjtu.edu.cn)
} 


\section{Introduction}

Thermal barrier coating (TBC) systems are widely applied in gas turbine engine blades, which provide the components with capability to operate at higher temperature over their melting points $[1,2]$. TBCs typically consist of an yttria stabilized zirconia (YSZ) top coat and a metallic bond coat (BC) interlayer. The thermally grown oxides (TGO) formed between the bond coat and top coat interface, preventing the superalloy components from oxidation and corrosion during service at high temperature $[1,3]$. It is widely reported that the failure of TBCs usually occurs at BC/TGO interface $[1,3$, 4]. Upon cooling, the elastic strain energy in TGO related to the mismatch of the thermal coefficient of expansion (CTE) is the major driving force for interface delamination. The elastic strain energy increases as TGO thickens. Additionally, the interfacial toughness at $\mathrm{BC} / \mathrm{TGO}$ interface decreases rapidly induced by $\mathrm{S}$ impurity segregation to interface and imperfections grow (e.g. interface pores and oxide intrusions) [5]. Eventually, the interface delamination occurs when the strain energy in TGO exceeds interfacial toughness [6]. Thus the slow TGO growth associated with a low TGO thickness and high interfacial toughness related to the effectively inhibiting effect of S segregation to interface and imperfections grow are crucial to durability of TBCs.

MCrAlY (M =Ni, Co or both) alloy has been widely used as the bond coat for the TBCs, due to its exceptional oxidation and corrosion resistance at high temperature $[1,3,4]$. Such application relies on the capability of the bond coats to form thermodynamically stable, slow growing, adherent and mechanically robust alumina scale upon thermal exposure. It is well established that the oxidation performance of bond coat is substantially affected by the minor additions of reactive element (RE) yttrium $(<1 \mathrm{wt} \%)$ $[7,8]$. The primary mechanisms of RE-effect are summarized as follows: (1) The detrimental $\mathrm{S}$ impurity can be tied up by yttrium, thereby maintaining the interfacial adhesion [1]; (2) The yttrium segregates to alumina grain boundaries, which can facilitate the inward transport of oxygen by the "block effect" on $\mathrm{Al}$ diffusion and hence lower the TGO growth rate[9]. The uniform yttrium distribution in the bond coat is 
anticipated to optimize this beneficial effect. However, the yttrium in a form of Ni-Y enriched precipitates segregates at grain boundaries of bond coat, which results from the low solid solubility of yttrium in the MCrAlY bond coat $[4,7,8,10]$. The localized yttrium enrichment results in the non-uniform yttrium distribution in the bond coat. These Ni-Y enriched precipitates in the bond coat will lead to several harmful effects. Firstly, a large amount of Y-Al oxides are incorporated into TGO due to the fast diffusion of yttrium. These Y-Al oxides provide short-circuit paths for inward oxygen transport, which lead to an enhanced TGO growth rate, thereby shorting time to TGO spallation $[3,7,10,11]$. Secondly, the localized yttrium enrichment contributes to the formation of interfacial imperfections (e.g. Y-rich oxide intrusions) [4, 7, 8]. These intrusions could be as the nucleation sites of initial interface delamination due to intrusions size increasing and the loss of interfacial adhesion during oxidation [4]. In conclusion, the homogeneity of yttrium distribution in the bond coat is of great importance to TGO growth rate and interfacial adhesion.

Up to now, only a few works are reported to suppress the excessive incorporation of Y$\mathrm{Al}$ oxides into TGO and the formation of Y-rich oxide intrusions at interface. It is suggested that the incorporation of Y-Al oxides into TGO can be reduced, when yttrium in the form of Y-rich oxide precipitates is present in the bond coat. Nevertheless, the effect of Y-rich oxide precipitates on the oxidation behavior of bond coat is not understood $[8,12]$. The Pt layer is deposited on the NiCoCrAlY bond coat to inhibit the formation of oxide intrusions at interface, which results in an improved TBC life time [13]. However, the cost of Pt is high and limits its industrial application. It has also been reported that the oxide intrusions can be reduced at initial oxidation stage ( $<1$ hour) when the grain size of $\beta-\mathrm{NiAl}$ phase is less than $3 \mu \mathrm{m}$ [11]. Nevertheless, the $\beta$-NiAl phase will inevitable coarsen due to the selective oxidation of $\beta$-NiAl phase upon exposure to longer time. Thus the oxide intrusions are still present at interface [4]. Considering the works mentioned above, it is of practical necessity to develop a simple and effective method to realize the uniform distribution of yttrium in the bond coat. In this contribution, the NiCoCrAlY bond coat with uniform distribution of yttrium is successfully fabricated by powder milling and spark plasma sintering (SPS). Although 
the bond coats are typically fabricated by air plasma spray (APS), high velocity air fuel (HVAF), vacuum plasma spray (VPS), low pressure plasma spray (LPPS) and electric beam physical vapor deposition (EBPVD) $[6,8,10,14]$, the SPS has attracted constantly increasing interest for fabricating multilayer samples for scientific studies due to its capability of fast sintering and limited grain growth. Already MCrAlY or Ptrich $\gamma-\mathrm{Ni} / \gamma^{\prime}-\mathrm{Ni}_{3} \mathrm{Al}$ bond coats have been successfully sintered on superalloy by SPS for TBCs application [15-17]. Recently, the SPS has been employed to fabricate the functionally graded YSZ/MCrAlY TBCs [18-20]. Furthermore, the reactive element oxides $\left(\mathrm{CeO}_{2}, \mathrm{Y}_{2} \mathrm{O}_{3}\right.$ and $\left.\mathrm{HfO}_{2}\right)$ dispersed $\beta$-NiAl coatings are produced by SPS and the oxidation behavior of coatings is investigated.

The objective of this study is to investigate and understand the effect of powder milling on the oxidation behavior of NiCoCrAlY bond coats, with a focus on the yttrium distribution in the bond coats. For this purpose, SPS is employed to fabricate fully dense bond coats prepared using two types of powder (as-received powder and milled powder). It is well demonstrated that the bond coat prepared from the milled powder exhibits significantly higher spallation resistance of TGO, compared with the bond coat prepared from the as-received powder. The isothermal oxidation test was carried out at $1150{ }^{\circ}$ Cin laboratory air. Both microstructure, oxidation rate, residual stress in TGO, S segregation at BC/TGO interface, and spallation lives are systematically evaluated. Eventually, the mechanisms of the enhanced spallation resistance of NiCoCrAlY bond coats after powder milling are discussed in detail, in terms of the driving force for delamination and interfacial toughness related to the yttrium distribution in the bond coat.

\section{Experimental procedure}

\subsection{Material and sample preparation}

Commercially available NiCoCrAlY powder (Amdry 365-2, Sulzer Metco) was used as starting material. Ball milling of the powder was performed at a rotation speed of 
$400 \mathrm{rpm}$ for 24 hours in a planetary ball mill under argon atmosphere. The milling was interrupted after 20 min to minimize the temperature increase. The bond coat prepared from the as-received powder (bond coat 1) and bond coat prepared from the milled powder (bond coat 2) were subsequently applied on the nickel-based Hastelloy ${ }^{\circledR} \mathrm{X}$ polycrystalline superalloy using SPS at $1050{ }^{\circ} \mathrm{C}$ for $10 \mathrm{~min}$ under a pressure of $50 \mathrm{MPa}$ in vacuum $\left(10^{-3} \mathrm{~Pa}\right)$, with a heating rate of $100{ }^{\circ} \mathrm{C} / \mathrm{min}$. The nominal compositions of the Hastelloy ${ }^{\circledR}$ X substrate and NiCoCrAlY powder are presented in Table 1.

Table 1. Nominal composition of Hastelloy® X substrate and NiCoCrAlY powder

\begin{tabular}{|c|c|c|c|c|c|c|c|c|c|c|}
\hline \multirow{2}{*}{ Material } & \multicolumn{10}{|c|}{ Element (wt \%) } \\
\hline & $\mathrm{Ni}$ & $\mathrm{Co}$ & $\mathrm{Cr}$ & $\mathrm{Al}$ & $\mathrm{Y}$ & $\mathrm{Fe}$ & Mo & W & $\mathrm{C}$ & Mn \\
\hline Hastelloy® X & 47 & 1.5 & 22 & / & / & 18 & 9 & 0.6 & 0.1 & $1^{*}$ \\
\hline NiCoCrAlY & 47.5 & 23 & 17 & 12 & 0.5 & / & / & / & / & / \\
\hline
\end{tabular}

\subsection{Isothermal oxidation}

The as-sintered samples were cut into $10 \times 10 \times 5 \mathrm{~mm}^{3}$ rectangle plates. To eliminate the rough surface, all bond coats were mechanically ground down to similar thickness $(\sim 150 \mu \mathrm{m})$ with final polishing of $0.05 \mu \mathrm{m}$ using standard metallographic approaches and thoroughly cleaned with acetone prior to oxidation. The isothermal oxidation was carried out at $1150{ }^{\circ} \mathrm{C}$ in a chamber furnace at atmosphere environment. The samples were removed from furnace after a required exposure time ranging from 0.5 hours to 200 hours, air-cooled outside the furnace at room temperature for approximately $15 \mathrm{~min}$.

\subsection{Characterization}

Scanning electron microscopy (SEM, FEI Nova Nano 230, Netherlands) was employed to characterize the microstructure of the samples. Chemical and phase analysis were executed using energy dispersive X-ray spectroscopy (EDS, Oxford Instruments) and X-ray diffraction (XRD, Ultima IV, Rigaku, Japan). 
The morphology and chemical composition of the bond coat prepared by milled powder were observed using transmission electron microscope (TEM, TALOS F200X, FEI, USA) and X-ray photoelectron spectroscopy (XPS, AXIS Ultra DLD, Kratos, Japan), respectively. Focused ion beam (FIB, GAIA3, Tescan, Czech Republic) combined with SEM was used for samples preparation of the milled bond coat for the HREM observations.

The quantitative depth profiles of elemental composition were determined by a radiofrequency glow discharge optical emission spectroscopy (GD-OES, GDA750HP, Germany). The concentration of every single element of interest was measured by a comparison with certified calibration samples that were commercially available. The measurements were performed using argon gas plasma with a RF power and pressure of $20 \mathrm{~W}$ and $2.5 \mathrm{hPa}$, respectively.

The electron backscatter diffraction (EBSD, Oxford Aztec HKL Max) system coupled with SEM was employed to measure the grain size. EBSD data was analyzed by HKL Channel 5 software. The residual stress in the TGO was measured using photoluminescence piezospectroscopy (PLPS) technique, using a Raman microscope (LabRAM HR, Horiba Jobin Yvon, France). Nd:YAG laser with a wavelength of 532 $\mathrm{nm}$ was used as excitation source. The laser beam was focused on the surface of the TGO through a $\times 50$ lens with a spot size of $\sim 3 \mu \mathrm{m}$. The spectra were fitted using a mixed Gaussian-Lorentzian function (Labspec software) to obtain the peak positions. The reference sample (stress free) was spalled TGO debris.

\section{Result}

\subsection{Microstructure of NiCoCrAIY powder before/after milling}

Fig. 1 shows the morphology of NiCoCrAlY powder before/after milling. As shown in Fig. 1a, the as-received powder is spherical and has a particle size distribution of from 46 to $85 \mu \mathrm{m}$. The uniform distribution of $\gamma$ phases (a solid solution of $\mathrm{Ni}, \mathrm{Co}$ and $\mathrm{Cr}$ ) and $\beta$-phases (aluminum rich $\mathrm{NiAl}$ ) are presented in Fig. $1 \mathrm{~b}$ and $1 \mathrm{c}$. After powder 
milling, the shape of milled powder is irregular with a rough surface (Fig. 1d). It should be mentioned that a large amount of $\beta$-phases dissolves into $\gamma$-matrix, due to supersaturated structure of milled powder (Fig. 1d and 1e) [21, 22]. Two obvious features in the XRD results (Fig. 2) between the as-received powder and the milled powder should be noted. First, the disappearance of $\beta$ peaks for the milled powder also indicates the dissolution of $\beta$-phases. Second, the broadening and reduced diffraction intensity of $\gamma$ and $\beta$ peaks for milled powder are observed, which are probably induced by grain refinement and non-uniform internal strain after powder milling[21]. However, after SPS, the $\beta$ peaks re-appear from the bond coat 2 , which is caused by the reprecipitation of the $\beta$-phase from the supersaturated $\gamma$-matrix. In addition, the $\gamma$ peaks of the bond coats become much sharper compared with those of the milled powder, as a result of recovery, recrystallization and grain growth during high temperature exposure [23].
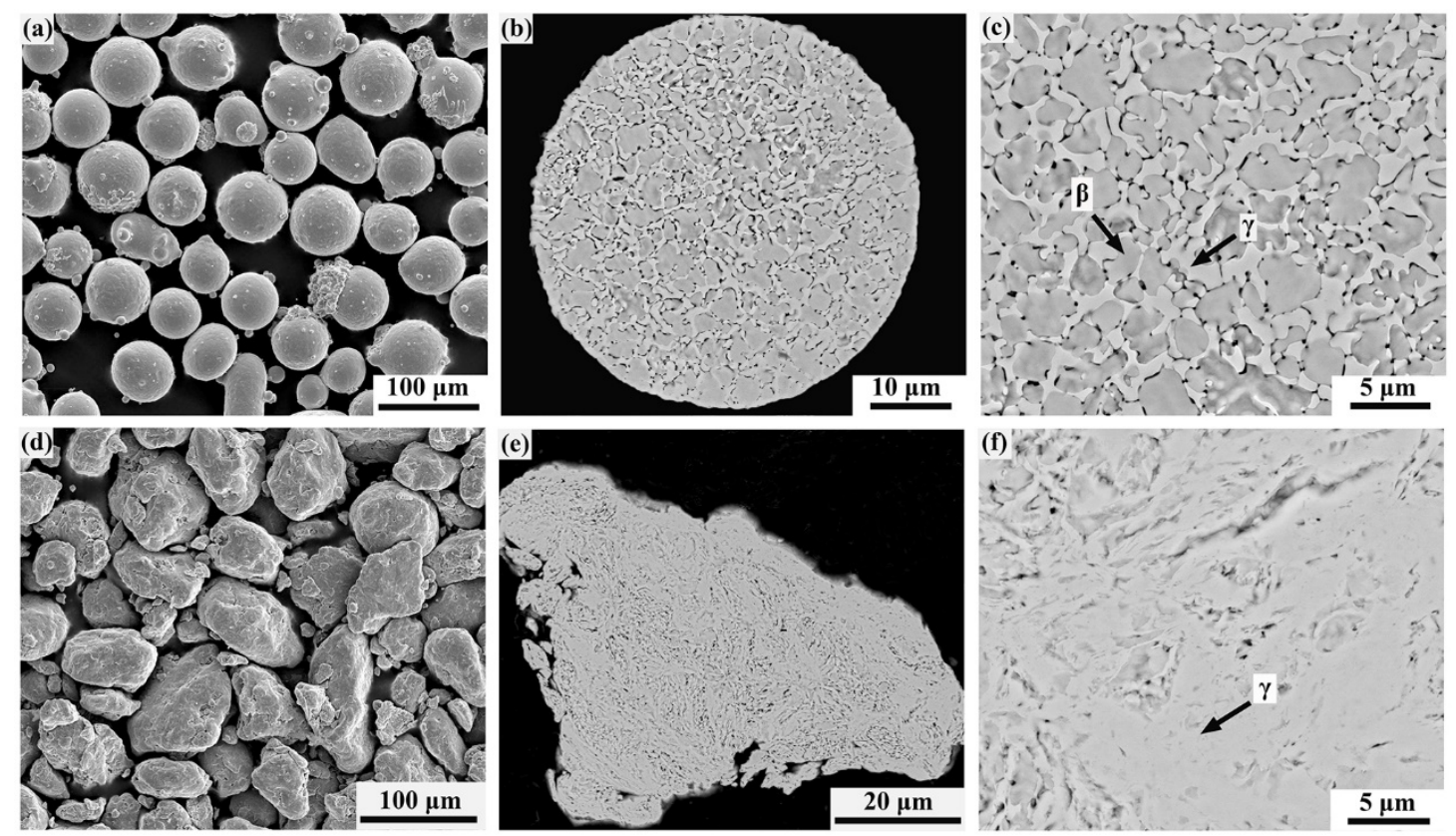

Fig.1. BSE images of the NiCoCrAlY powders before and after milling: (a) morphology of the as-received powder; (b) polished cross section of as-received powder; (c) high magnification image of (b) showing the two-phase microstructure; (d) morphology of the milled powder; (e) polished cross section of milled powder; (f) high magnification image of (e) showing the grain structure. The polished samples were etched using a mixture of 50 vol. $\% \mathrm{HCl}, 50$ vol. \% ethanol with 5 wt. $\% \mathrm{CuCl}_{2}$ dissolved [9]. 


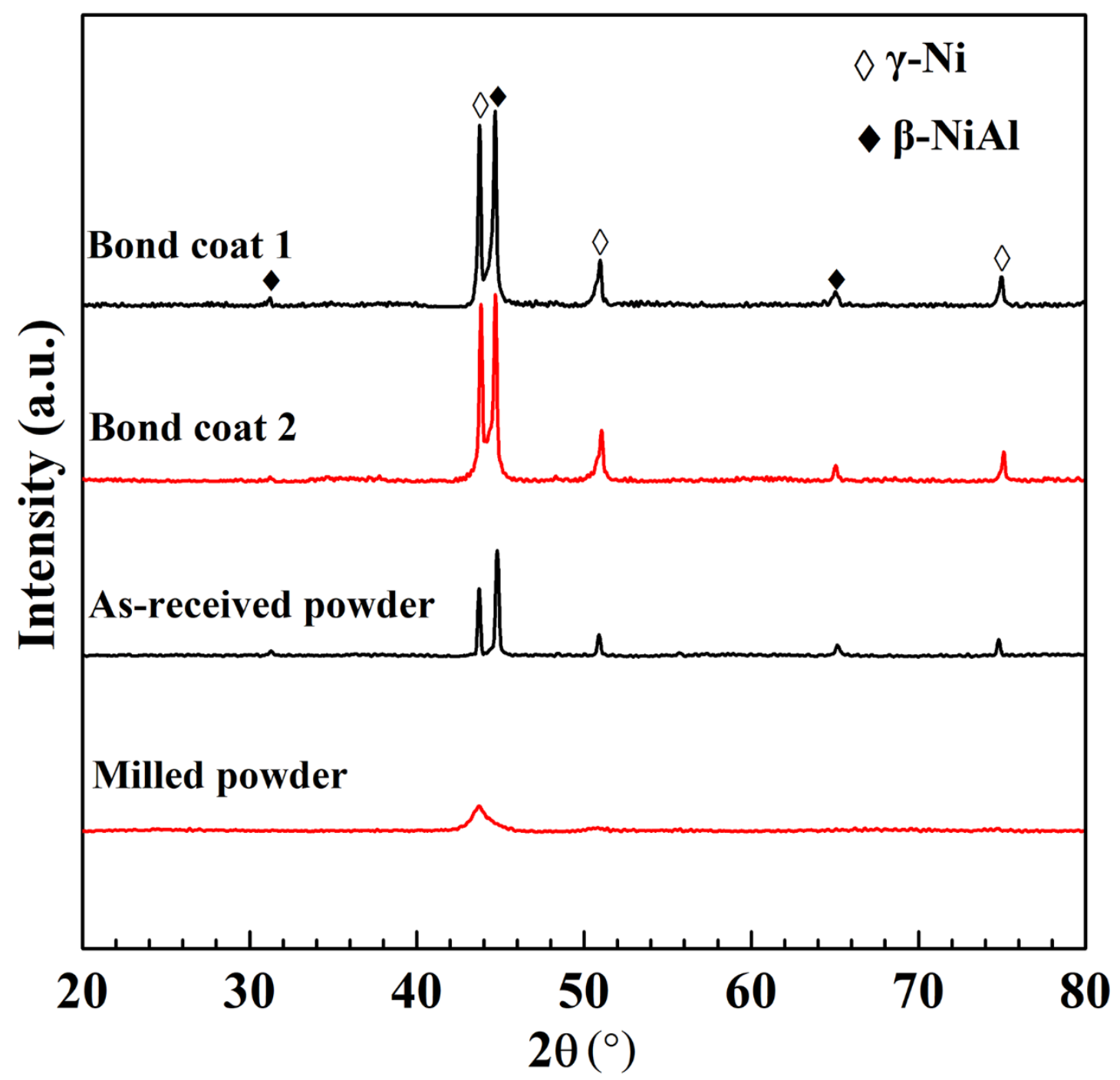

Fig 2. XRD results of milled powder, as-received powder, bond coat 1 and bond coat 2.

\subsection{Microstructure of NiCoCrAIY bond coats fabricated by SPS}

The cross-sectional SEM micrographs of NiCoCrAlY bond coats after polishing are shown in Fig. 3. As displayed in Fig. 3a and 3c, the bond coats thickness is polished to about $150 \mu \mathrm{m}$. The two-phase microstructure are observed in both specimens, which comprises of $\beta$-NiAl (grey contrast) and $\gamma$-Ni (light contrast) phases, as shown in Fig. $3 \mathrm{~b}$ and $3 \mathrm{~d}$. Furthermore, the bond coats are fully dense without pores or internal oxidation. The distribution of element $\mathrm{Ni}, \mathrm{Al}$ and $\mathrm{Co}$ is almost same for two types of bond coats according to the elemental maps. For the bond coat 1 , the yttrium in the form of Ni-Y enriched precipitates $(300 \sim 700 \mathrm{~nm})$ segregates to $\gamma / \beta$ or $\gamma / \gamma$ grain boundaries. This result is in agreement with the bond coat deposited by LPPS [8], 
VPS[7, 24], and EB-PVD[10]. However, the yttrium segregation is hardly detected in the bond coat 2. Thus further investigations should be made to determine the distribution and form of yttrium in the bond coat 2 .

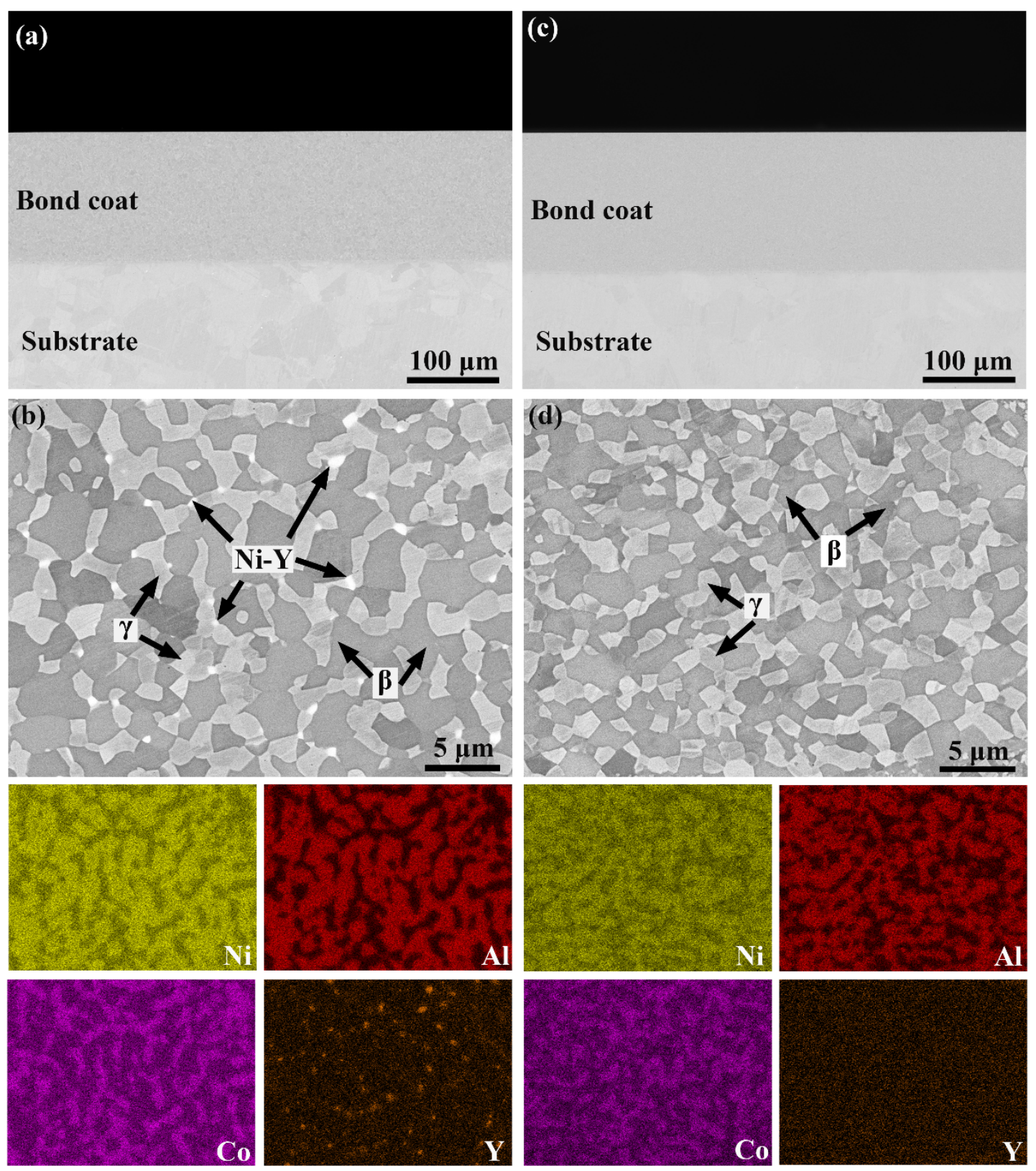

Fig. 3. The cross-sectional SEM micrographs of NiCoCrAlY bond coats: (a) bond coat 1 ; (c) bond coat 2; (b, d) high magnification micrographs of (a, c) showing the twophase microstructure and corresponding elemental maps of $\mathrm{Ni}, \mathrm{Co}, \mathrm{Al}$, and $\mathrm{Y}$.

\subsection{The distribution and form of yttrium in the bond coat 2}

The high magnification micrograph after FIB etching presented in Fig .4 reveals the 
microstructure of bond coat 2 in detail. Fine, nanoscale Ni-Y enriched precipitates (indicated by white arrows) are uniformly distributed at the grain boundaries of bond coat 2 . It should be specially noted that the size of $\mathrm{Ni}-\mathrm{Y}$ enriched precipitates (50 to $150 \mathrm{~nm}$ ) is much smaller in the bond coat 2, compared with Ni-Y enriched precipitates (300 to $700 \mathrm{~nm}$ ) in the bond coat 1 .

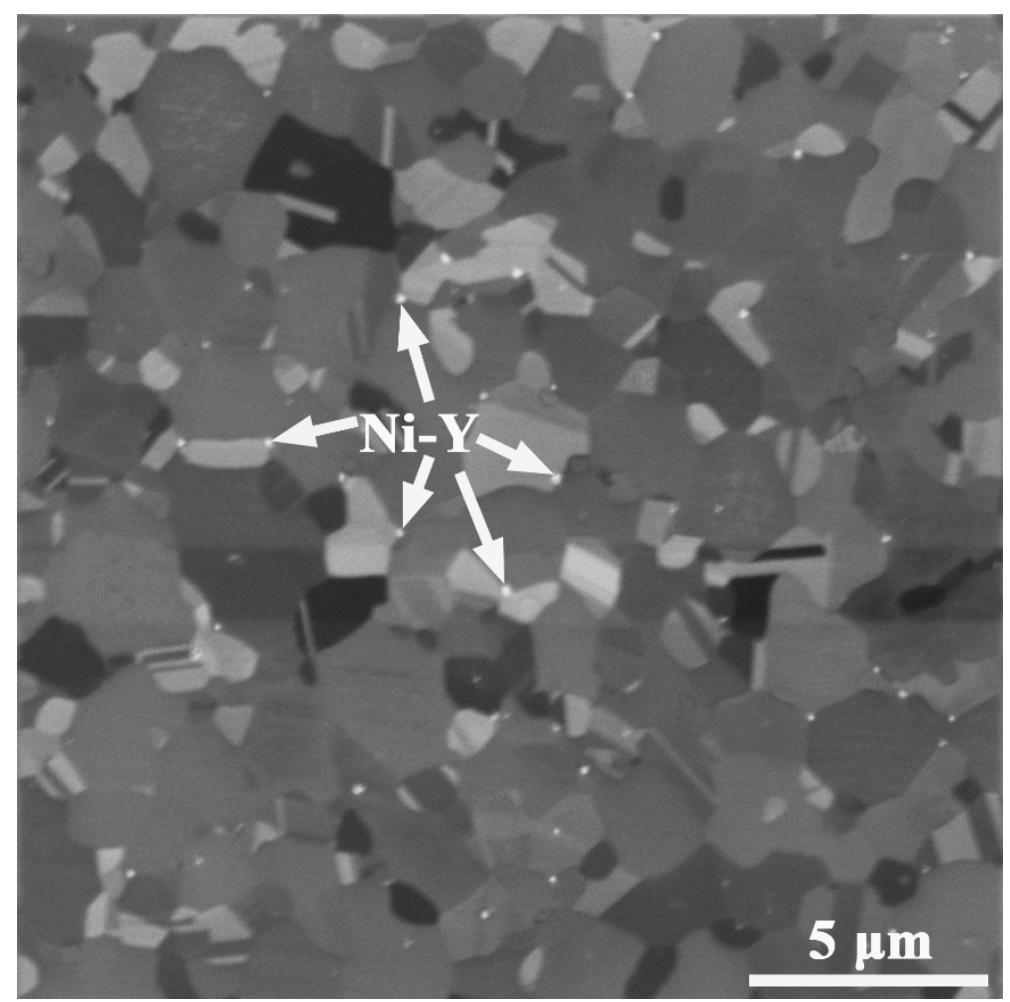

Fig. 4. The high magnification SEM micrographs of bond coat 2 after FIB etching.

TEM is employed to examine the reason for the decrease in the size of Ni-Y enriched precipitates in the bond coat 2, as shown in Fig .5. The thin lamella milled by FIB is presented in Fig. 5a, coupled with the bright-field (BF) TEM image (Fig. 5b) and highangle annular dark-field (HAADF) image (Fig. 5c). As displays in Fig. 5c, Al enriched phase and Co enriched phase are $\beta$ phase (grey contrast) and $\gamma$ phase (light contrast), respectively, in combination with elemental maps. The concentration of elements $\mathrm{Y}$ and $\mathrm{O}$ observed in Fig. 5g, 5h, and 5i indicates that a part of yttrium in the form of nanosized $\mathrm{Y}_{2} \mathrm{O}_{3}$ particles $(5 \mathrm{~nm}$ to $30 \mathrm{~nm})$ is uniformly dispersed at $\gamma / \beta$ grain boundaries as well as in $\beta$ grains (Fig. 5c). Similar $\mathrm{Y}_{2} \mathrm{O}_{3}$ particles are found in the NiCrAlY alloy prepared by SPS using cryomilling powder [25]. In short, the yttrium in the form of 
fine Ni-Y enriched precipitates and nano-sized $\mathrm{Y}_{2} \mathrm{O}_{3}$ particles is uniformly distributed in the bond coat 2 .

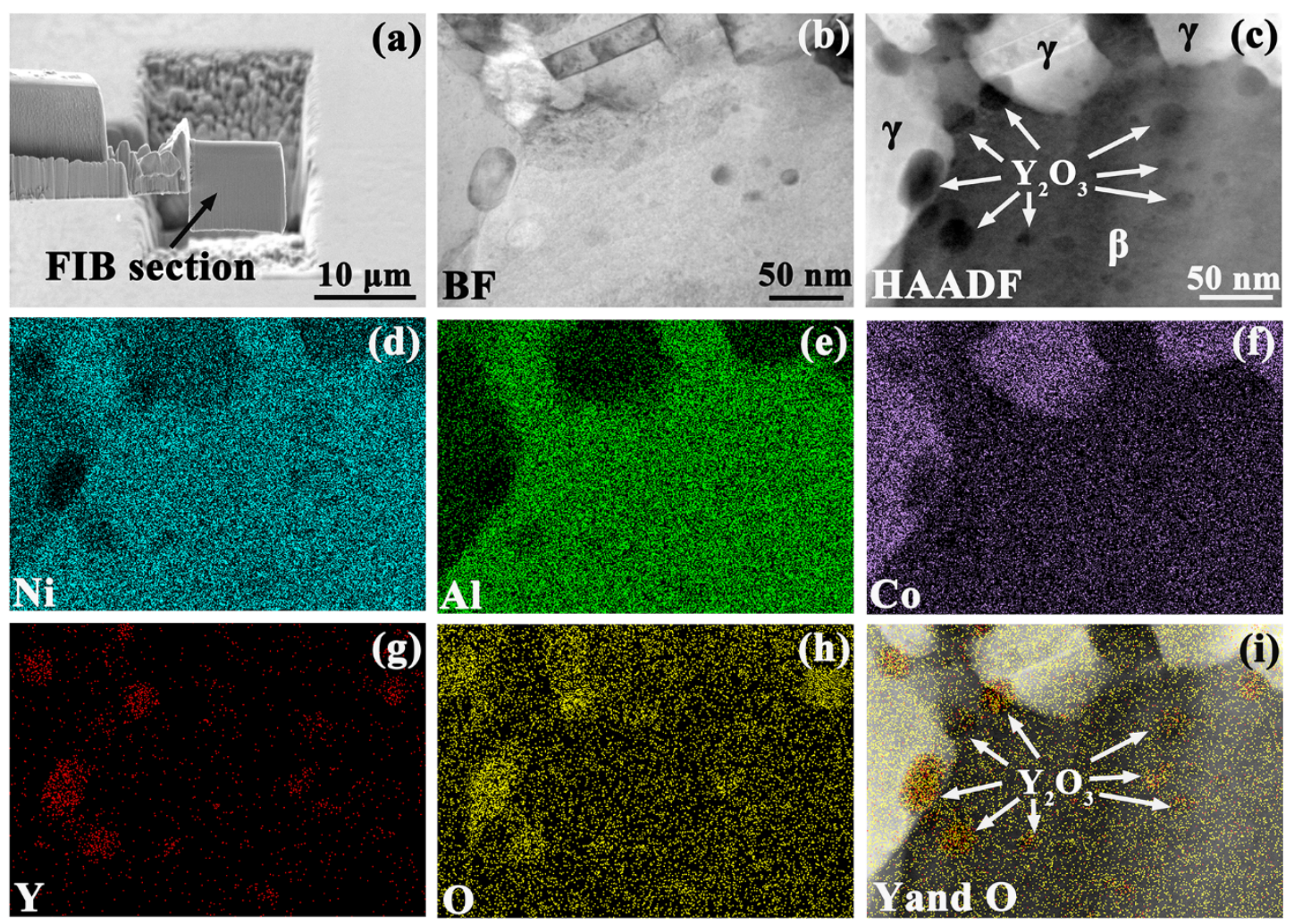

Fig .5. TEM analysis of the bond coat 2. (a) thin lamella milled by FIB; (b) bright-field (BF) TEM image; (c) high-angle annular dark-field (HAADF) STEM image; (d, e, f, g and h) EDS maps of Ni, Al, Co, Y and O, respectively and (i) superimposed map of Y and $\mathrm{O}$.

Fig .6 displays the typical EBSD maps of bond coats. Both bond coats comprised of $\gamma$ Ni phase and $\beta$-NiAl phase. Grain sizes were evaluated by channel 5 software, which is presented in Table 2. Grain sizes are slightly reduced after milling and SPS, but they are generally in the order of same magnitude. Plenty of twins are observed in the fcc- $\gamma$ phase of bond coat 2 , which can be attributed to the severe plastic deformation condition (e.g. powder milling) and sintering at high temperature (e.g. SPS) [26, 27]. 

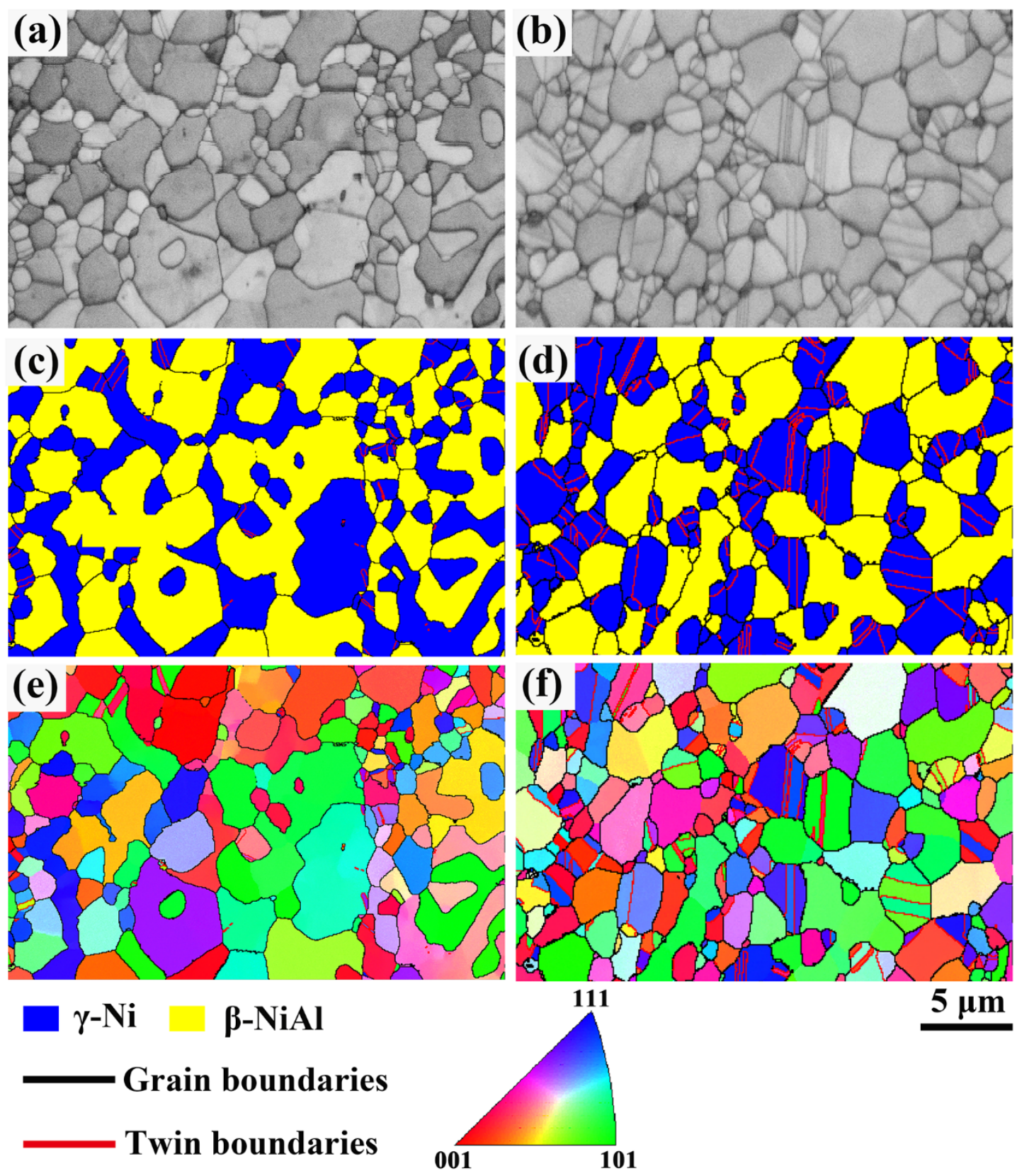

Fig. 6. The typical EBSD analysis of bond coats. The (a, c, e) showing the band contrast maps, phase contrast maps, and inverse pole figure (IPF) maps of the bond coat 1 , respectively; the $(\mathrm{b}, \mathrm{d}, \mathrm{f})$ showing the band contrast maps, phase contrast maps, and inverse pole figure maps of the bond coat 2, respectively; The yellow and blue areas in the phase contrast maps are the $\beta$ and $\gamma$ phases, respectively. The color in Fig.6e and $\mathrm{f}$ represents the crystallographic directions of the $\gamma$ and $\beta$-grains parallel to the surface normal direction. The red and black lines in the IPF color maps are twin boundaries and grain boundaries.

Table 2. The $\gamma$-Ni phase and $\beta$-NiAl phase grain size of bond coat. 


\begin{tabular}{ccc}
\hline Material & $\begin{array}{c}\gamma \text {-Ni phase } \\
\text { grain size, } \mu \mathrm{m}\end{array}$ & $\begin{array}{c}\beta \text {-NiAl phase } \\
\text { grain size, } \mu \mathrm{m}\end{array}$ \\
\hline bond coat 1 & $1.9385 \pm 0.5162$ & $2.7342 \pm 0.7491$ \\
bond coat 2 & $1.2062 \pm 0.4483$ & $1.6106 \pm 0.6884$ \\
\hline
\end{tabular}

\subsection{Spallation resistance}
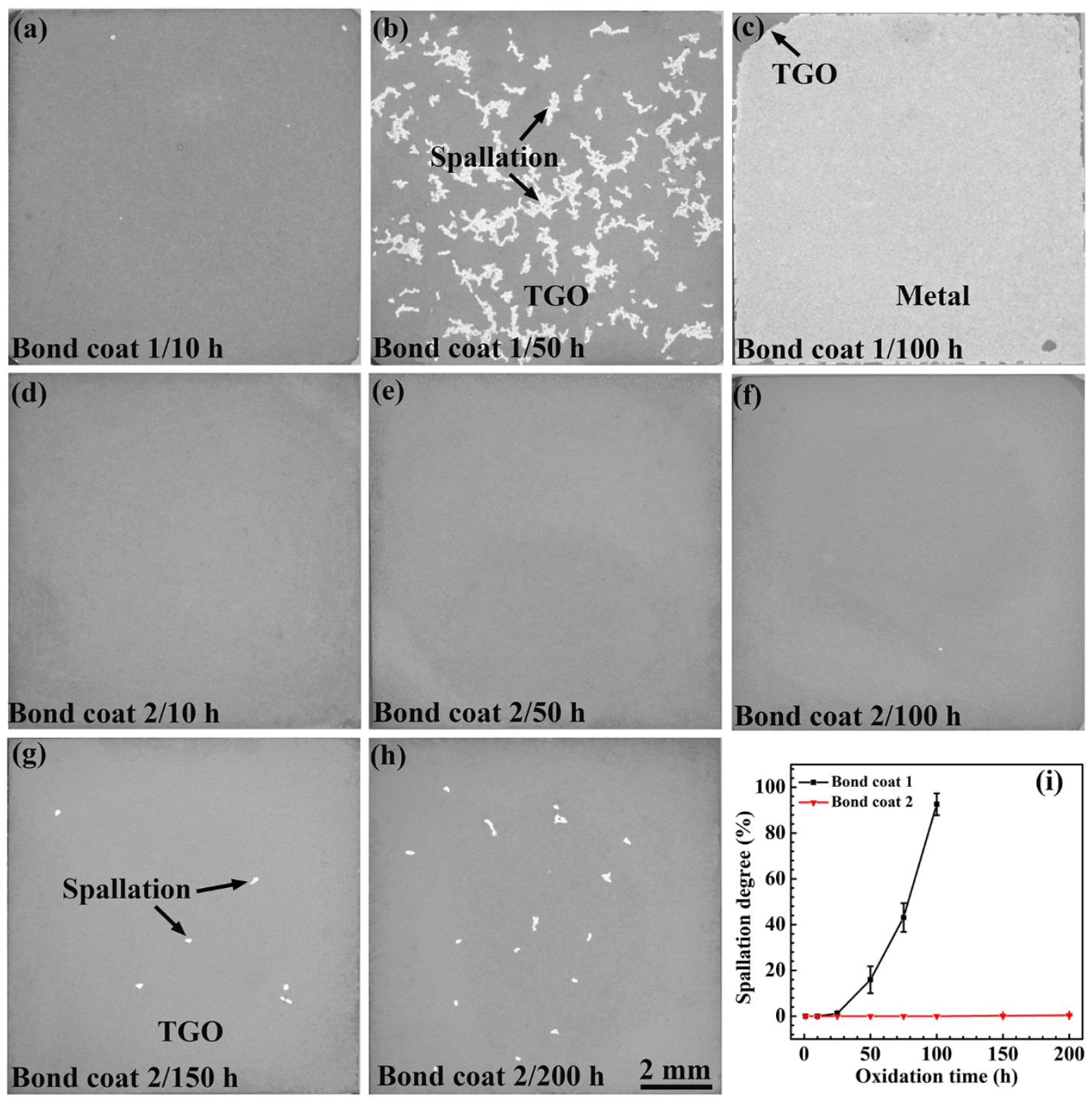

Fig. 7. The optical micrographs of the TGO: $(a, b$, and $c)$ formed on bond coat $1,(d, e$, $\mathrm{f}$, and g) formed on bond coat 2 after isothermal oxidation at $1150{ }^{\circ} \mathrm{C}$. (i) TGO spallation degree of bond coats (defined by the ratio between spalled area and the whole area of the TGO) as a function of oxidation time at $1150{ }^{\circ} \mathrm{C}$.

To evaluate the oxidation resistance of the two types of bond coats, isothermal 
oxidation tests were carried out at $1150{ }^{\circ} \mathrm{C}$. The surface morphologies of TGO formed on the bond coats after isothermal oxidation and the evaluated TGO spallation degree as a function of oxidation time are shown in Fig. 7. For the bond coat 1, about a $20 \%$ TGO spallation after 50 hours oxidation (Fig. 7b). The TGO spallation increases rapidly with the oxidation time and reaches $\sim 90 \%$ after 100 hours oxidation (Fig. 7c). However, for the bond coat 2, the TGO is almost intact after 100 hours oxidation (Fig. 7f). Even after 200 hours oxidation, only local TGO spallation about a $0.4 \%$ delamination occurs (Fig. 7h). Therefore, the spallation resistance of NiCoCrAlY bond coat is significantly improved after powder milling.

\subsection{TGO microstructure}

Fig. 8 shows the surface morphologies of TGO spallation for the bond coat 1 after 50 hours oxidation. It is clearly exhibited that TGO delamination occurs primarily at the $\mathrm{BC} / \mathrm{TGO}$ interface and around the thickness imperfections (e.g. oxide intrusions). The micro-cracks in the TGO observed in Fig. 8b suggest a buckling failure, releasing elastic strain energy in the TGO upon cooling to room temperature [4, 28]. As presented in Fig. $8 \mathrm{c}$ and $8 \mathrm{e}$, plenty of oxidation intrusions are observed at the spalled interface. 8 The representative oxidation intrusions displayed in Fig. $8 \mathrm{~d}$ and $8 \mathrm{f}$ show a porous and heterogeneous microstructure, which will be analyzed in greater detail later.

To determine the composition and microstructure of oxide intrusions, the EDS maps are shown in Fig. 9. In combination with the EDS maps, the Y-Cr enriched oxides and spinel phases are found in the porous microstructure. The $\mathrm{Y}-\mathrm{Cr}$ enriched oxides are likely to be $\mathrm{YCrO}_{3}$, which is compatible with $\mathrm{Cr}_{2} \mathrm{O}_{3}$ enriched area and can cause considerable interface roughening [29]. Thus the pores in the oxide intrusions (Fig. 9d and 9f) probably come from the volume contraction due to the formation of Y-Cr enriched oxides and spinel phases(e.g. $\left.\mathrm{Ni}(\mathrm{Al}, \mathrm{Co})_{2} \mathrm{O}_{4}\right)$. The porous microstructure at interface and brittle spinel oxides in TGO will undermine the interface adhesion [30]. Similar interfacial pores are also observed in EB-PVD TBC, which can contribute to the degradation of interfacial toughness [31]. 

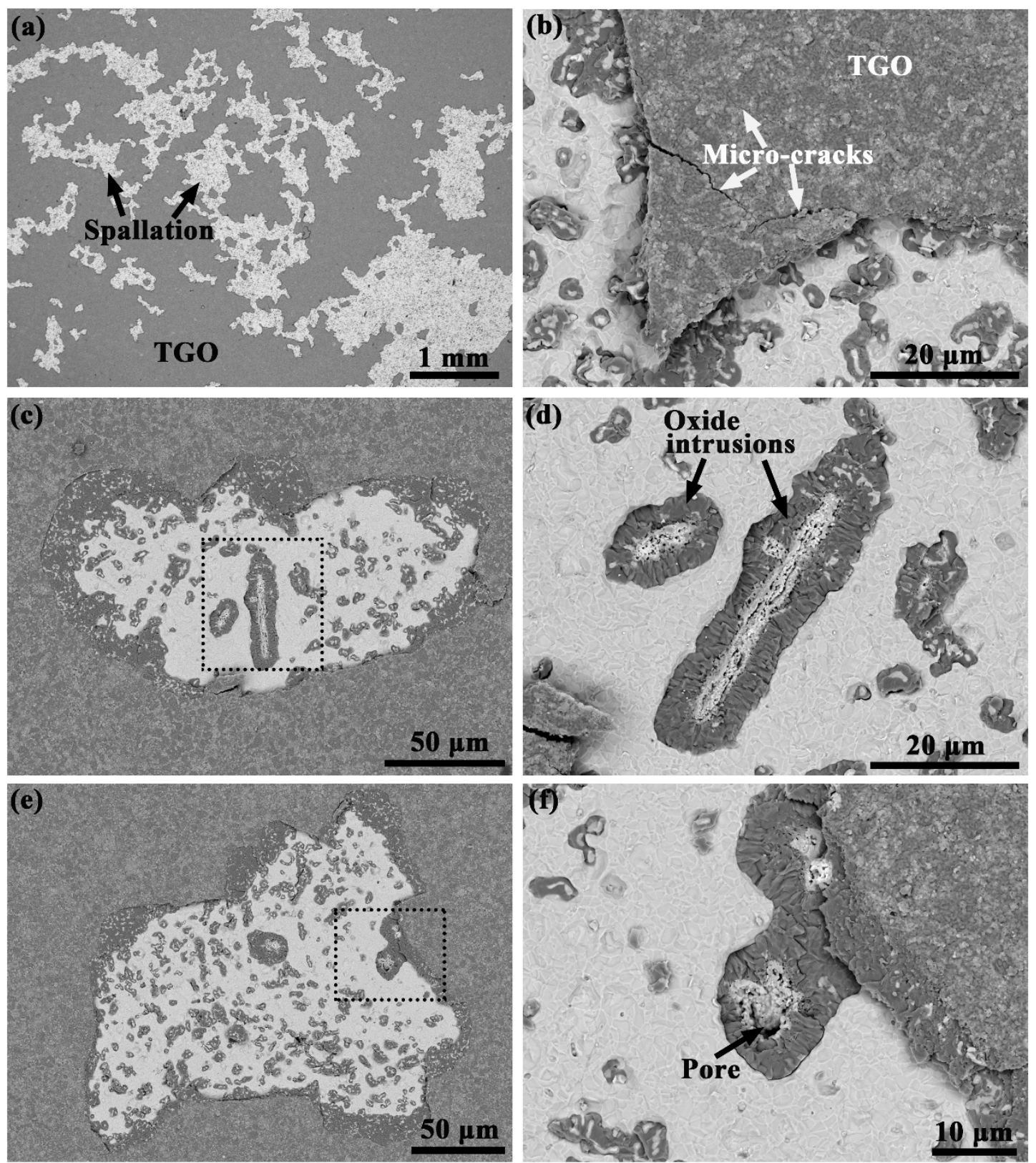

Fig. 8. BSE micrographs of the bond coat 1 after 50 hours oxidation showing the morphologies: (a) TGO spallation region, (b) the micro-cracks in the TGO, (c and e) the isolated TGO spallation corresponding to ( $\mathrm{d}$ and $\mathrm{f}$ ) the representative oxidation intrusions at the spalled interface. 

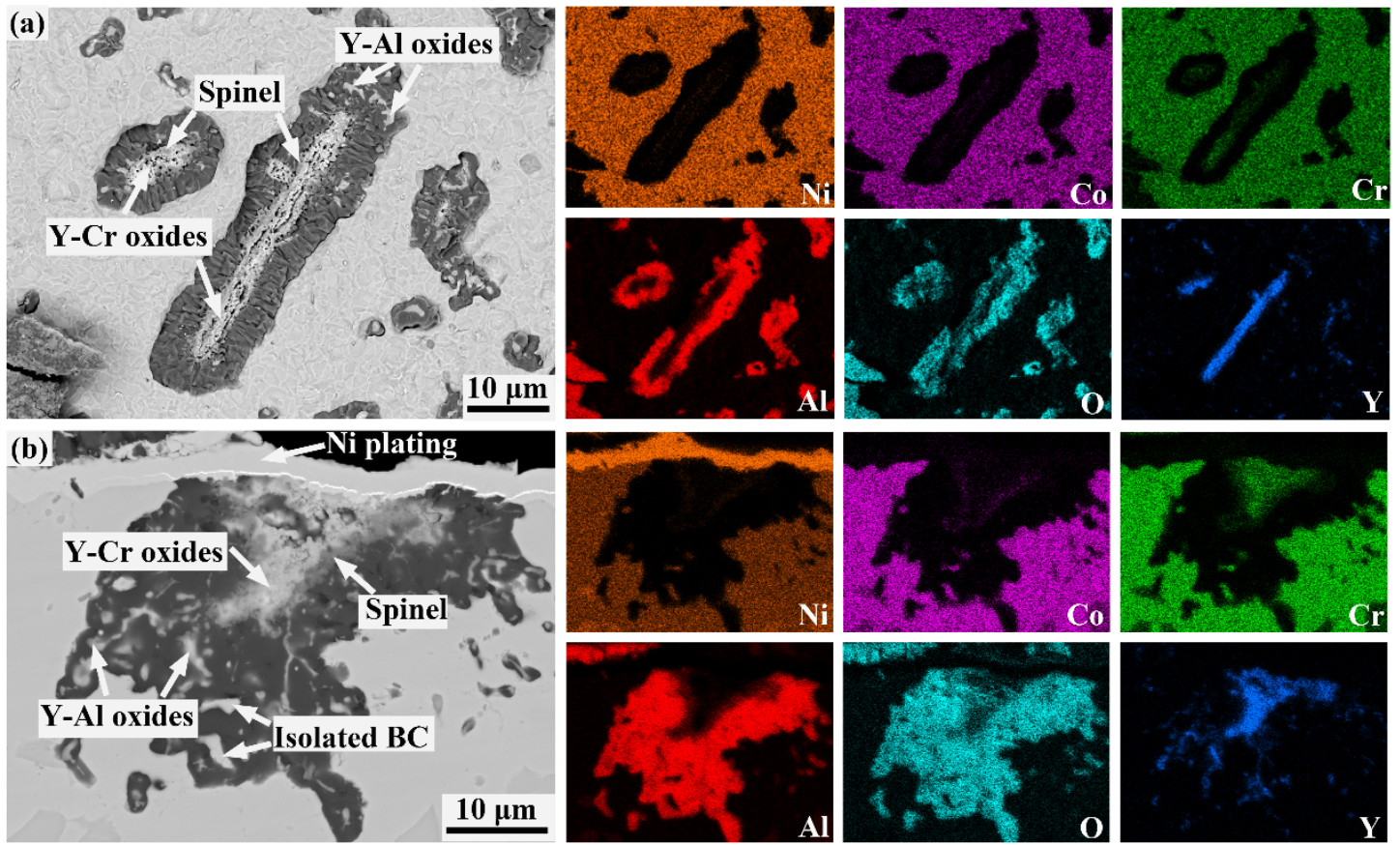

Fig. 9. (a) The surface composition maps and (b) cross-sectional composition maps of an oxide intrusion for the bond coat 1 after 50 hours oxidation.

After 150 hours oxidation, minor quantity of TGO delamination starts to occur for the bond coat 2 (Fig. 7g). Thus surface morphologies of TGO spallation for the bond coat 2 after 150 hours oxidation are presented in Fig. 10. The spalled interface is clean for bond coat 2 , where the interfacial pores and oxidation intrusions are hardly detected.
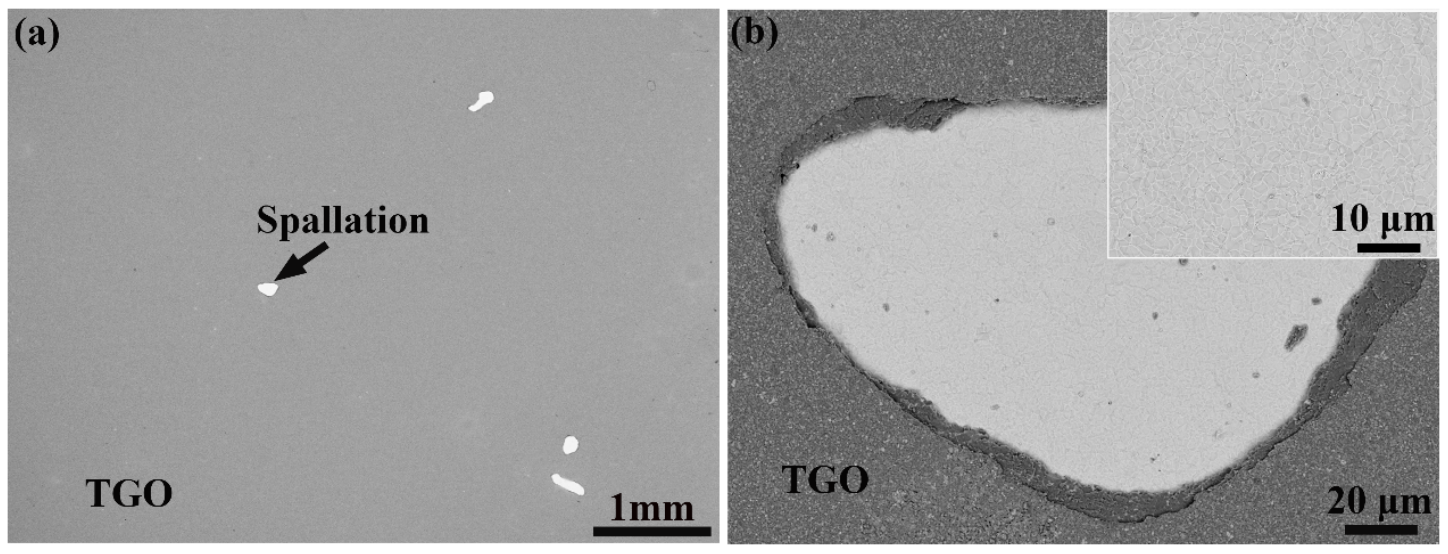

Fig. 10. BSE micrographs of the bond coat 2 after 150 hours oxidation showing the morphologies: (a) the TGO surface, (b) TGO spallation region. The inserted micrograph in (b) showing the enlarged morphology of spalled interface.

The evolution of TGO composition and BC/TGO interface morphology as a function of oxidation time are shown in Fig. 11. For the bond coat 1, the TGO primarily consists 
of $\mathrm{Al}_{2} \mathrm{O}_{3}$ and a large amount of $\mathrm{Y}-\mathrm{Al}$ oxides (bright phases). Meanwhile, the rough $\mathrm{BC} / \mathrm{TGO}$ interface is observed, which is induced by the Y-enriched oxide intrusions extending into bond coat (Fig. 11a and 11b). These results are quite well in agreement with the previous investigations for NiCoCrAlY oxidation $[4,7,10]$. For the bond coat 2, the TGO comprises of $\mathrm{Al}_{2} \mathrm{O}_{3}$, except for a small amount of fine $\mathrm{Y}-\mathrm{Al}$ oxides (Fig. 7c - 7f). In addition, the BC/TGO interface is flat and smooth, even after 200 hours oxidation. The tremendous differences in TGO composition and BC/TGO interface morphology for two types of bond coats are related to the distribution of yttrium in the bond coats.

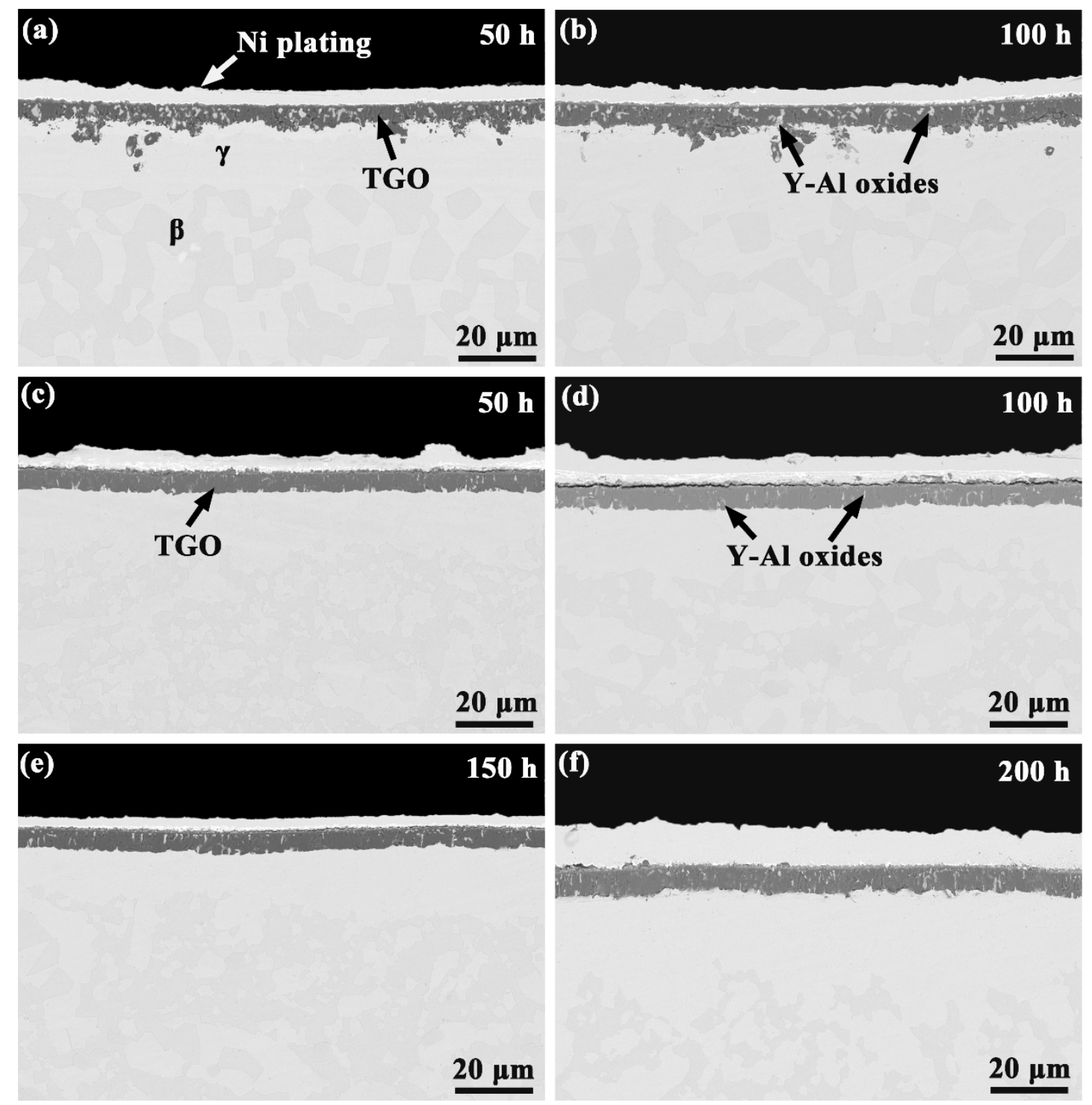

Fig. 11. Cross-sectional BSE micrographs of: $(a, b)$ TGO formed on the bond coat 1 and (c, d, e and f) TGO formed on the bond coat 2 as a function of oxidation time. 
To determine the TGO microstructure for two types of bond coats, the fractured crosssectional micrographs of TGO after $50 \mathrm{~h}$ oxidation are presented in Fig. 12. For the bond coat 1, in the area where large-sized $\mathrm{Y}-\mathrm{Al}$ oxides are incorporated into $\mathrm{Al}_{2} \mathrm{O}_{3}$ matrix after 50 hours oxidation, the TGO shows a mixed structure of equiaxed grains and columnar grains (Fig 12a). For the bond coat 2, only fine Y-Al oxides primarily exist along $\mathrm{Al}_{2} \mathrm{O}_{3}$ grain boundaries after 50 hours oxidation (Fig 12b). A duplex microstructure of TGO (outer exquiaxed grains and inner columnar grains) covers whole surface of bond coat 2. The double-layer microstructure results from the dominant growth mechanism by inward oxygen transport [9]. In addition, the pores at $\mathrm{Al}_{2} \mathrm{O}_{3}$ grain boundaries are detected for the bond coat 2 , which probably due to the spallation of $\mathrm{Y}-\mathrm{Al}$ oxides from the $\mathrm{Al}_{2} \mathrm{O}_{3}$ grain boundaries during the TGO fracture. After 150 hours oxidation for bond coat 2, the Y-Al oxides remains fine (20 150 nm) and are uniformly distributed at $\mathrm{Al}_{2} \mathrm{O}_{3}$ grain boundaries, as shown in Fig. 12c and $12 \mathrm{~d}$. The differences in the TGO microstructure for two bond coats are related to TGO growth mechanism, which will be discussed following in detail.
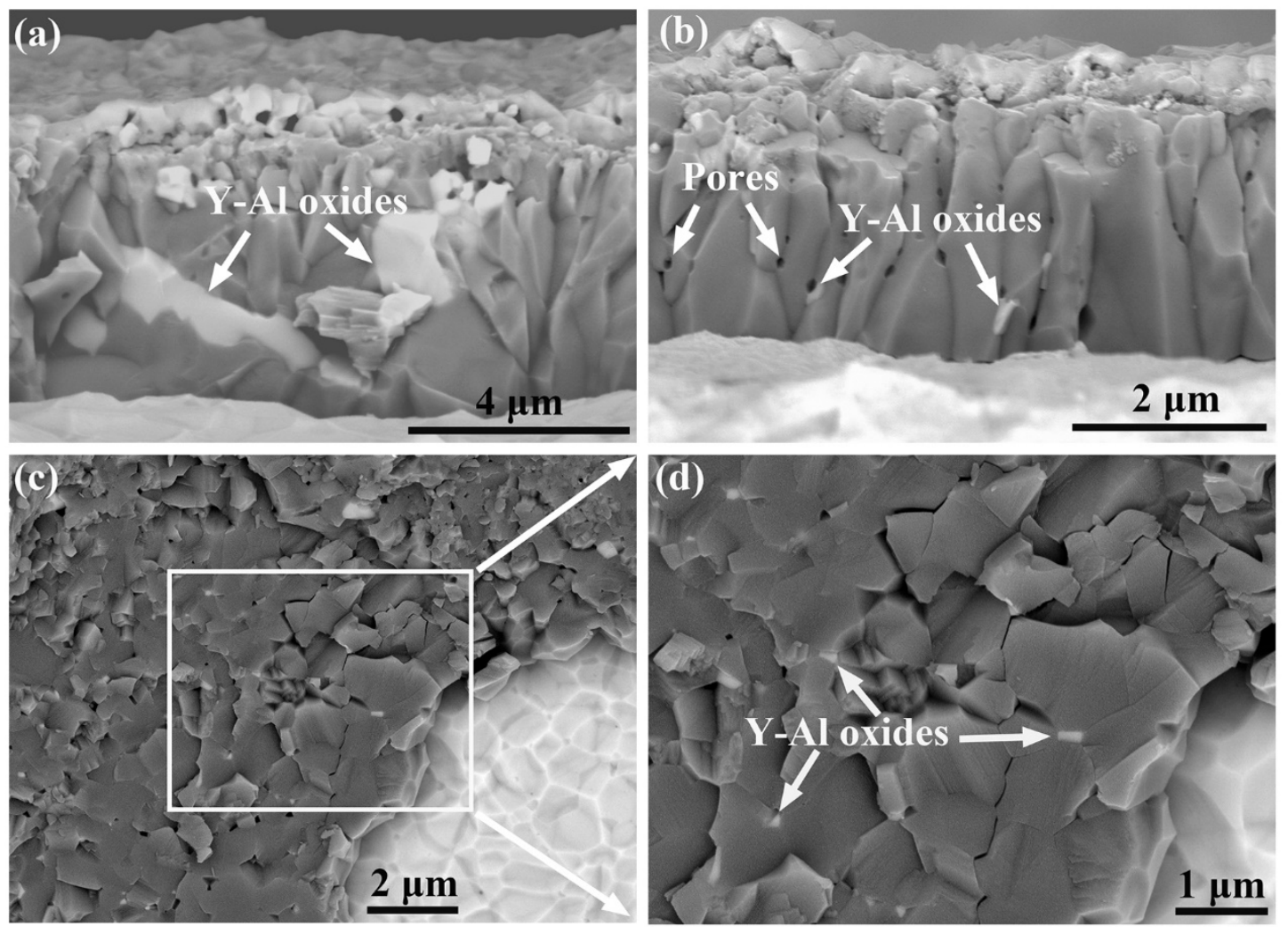

Fig. 12. The fractured cross-sectional BSE morphologies of: (a) TGO formed on the 
bond coat 1, (b) TGO formed on the bond coat 2 after isothermal oxidation at $1150{ }^{\circ} \mathrm{C}$ for 50 hours. (c, d) show the surface morphologies of TGO fractured section formed on the bond coat 2 after isothermal oxidation at $1150{ }^{\circ} \mathrm{C}$ for 150 hours.

Fig. 13 presents the phase composition of TGO formed on the bond coats after oxidation for 1 hours, 10 hours, and 50 hours. For the bond coat 1, the TGO primarily consists of $\alpha-\mathrm{Al}_{2} \mathrm{O}_{3}$ and $\mathrm{Y}-\mathrm{Al}$ oxides. The $\mathrm{Y}-\mathrm{Al}$ oxides in the TGO was identified to be $\mathrm{YAlO}_{3}$ (YAP). In addition, the amount of YAP constantly increases as oxidation time increases. For the bond coat 2, the YAP is hardly detected, probably due to the low concentration. These results are consistent with the observations in the Fig. 11.

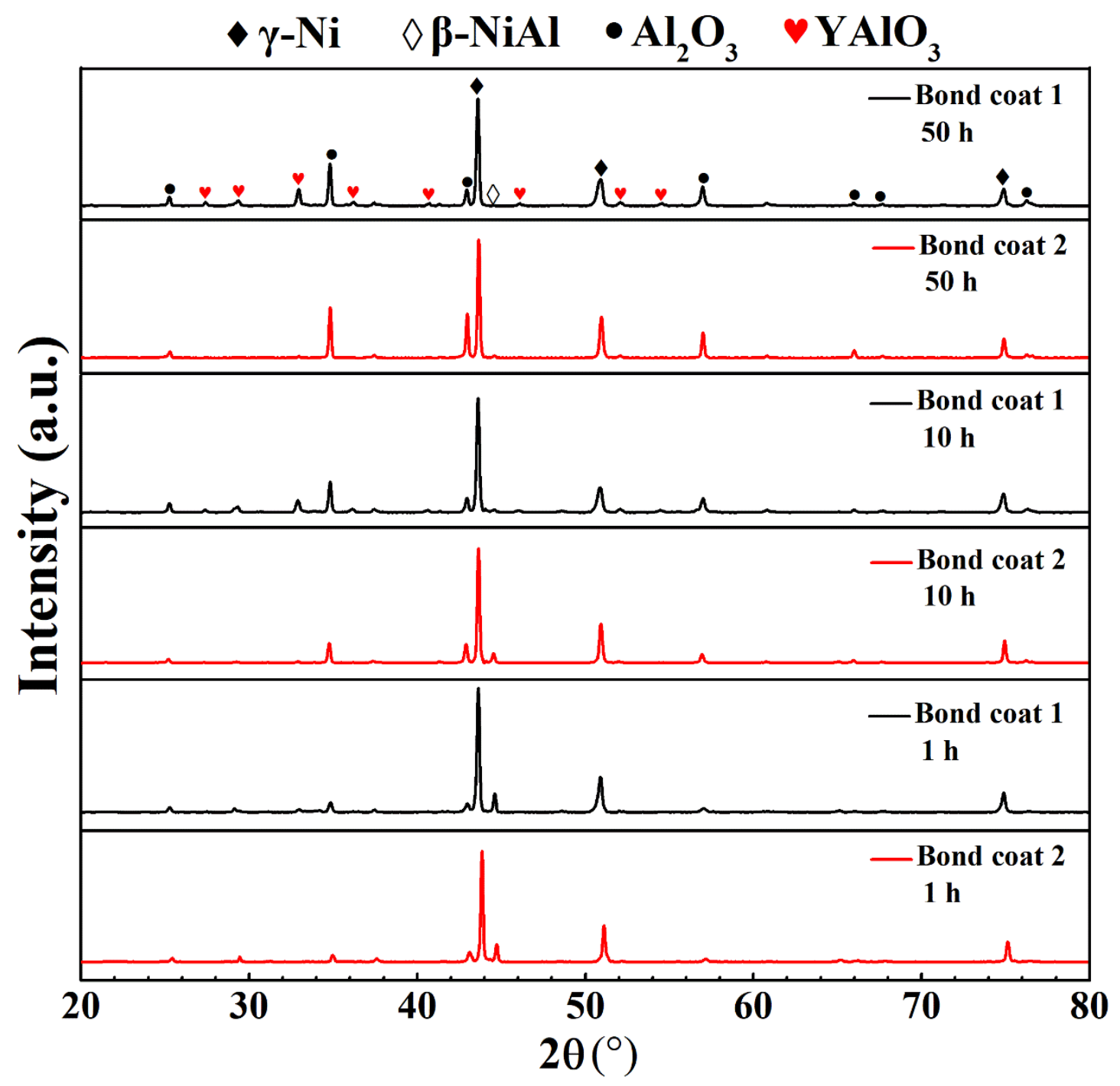

Fig. 13. The XRD results of the bond coats after oxidation at $1150{ }^{\circ} \mathrm{C}$ for 1 hours, 10 hours, and 50 hours. 


\subsection{Oxide growth kinetics}

Fig. 14 plots the average TGO thickness formed on the bond coats versus the square root of the oxidation time at $1150{ }^{\circ} \mathrm{C}$, which is measured at 50 equidistance points distributed through the cross-sectional area of the TGO divided by the length of interface with a step size of $20 \mu \mathrm{m}$. The error bar is the standard deviation of 50 equidistance points. For the bond coat 1 , the significantly larger error bar indicates nonuniform TGO thickness, which is induced by interface roughening (Fig. 11a and b). For the bond coat 2, the TGO thickness slowly and uniformly increases, as shown in Fig. $11 \mathrm{c}-\mathrm{f}$.

The linear fitting is used to fit the data and yields the growth rate constant:

$$
h^{2}=2 \mathrm{k}_{\mathrm{p}} t
$$

where $\mathrm{h}$ is the average TGO thickness; $\mathrm{t}$ is the oxidation time and $\mathrm{k}_{\mathrm{p}}$ is the parabolic growth rate constant (units of $\mathrm{cm}^{2} \mathrm{~s}^{-1}$ ). The $\mathrm{k}_{\mathrm{p}}$ value for the bond coat 1 is $6.2 \times 10^{-13} \mathrm{~cm}^{2}$ $\mathrm{s}^{-1}$, which is almost consistent with that of NiCoCrAlY bond coat with a similar composition produced by plasma activated electron beam-physical vapor deposition(PA EB-PVD) [32]. For the bond coat 2, the $\mathrm{k}_{\mathrm{p}}$ value $\left(2.8 \times 10^{-13} \mathrm{~cm}^{2} \mathrm{~s}^{-1}\right)$ is reduced by $\sim 55 \%$, as compared with the bond coat 1 . This result indicates clearly that the bond coat 2 shows a lower oxidation rate. 


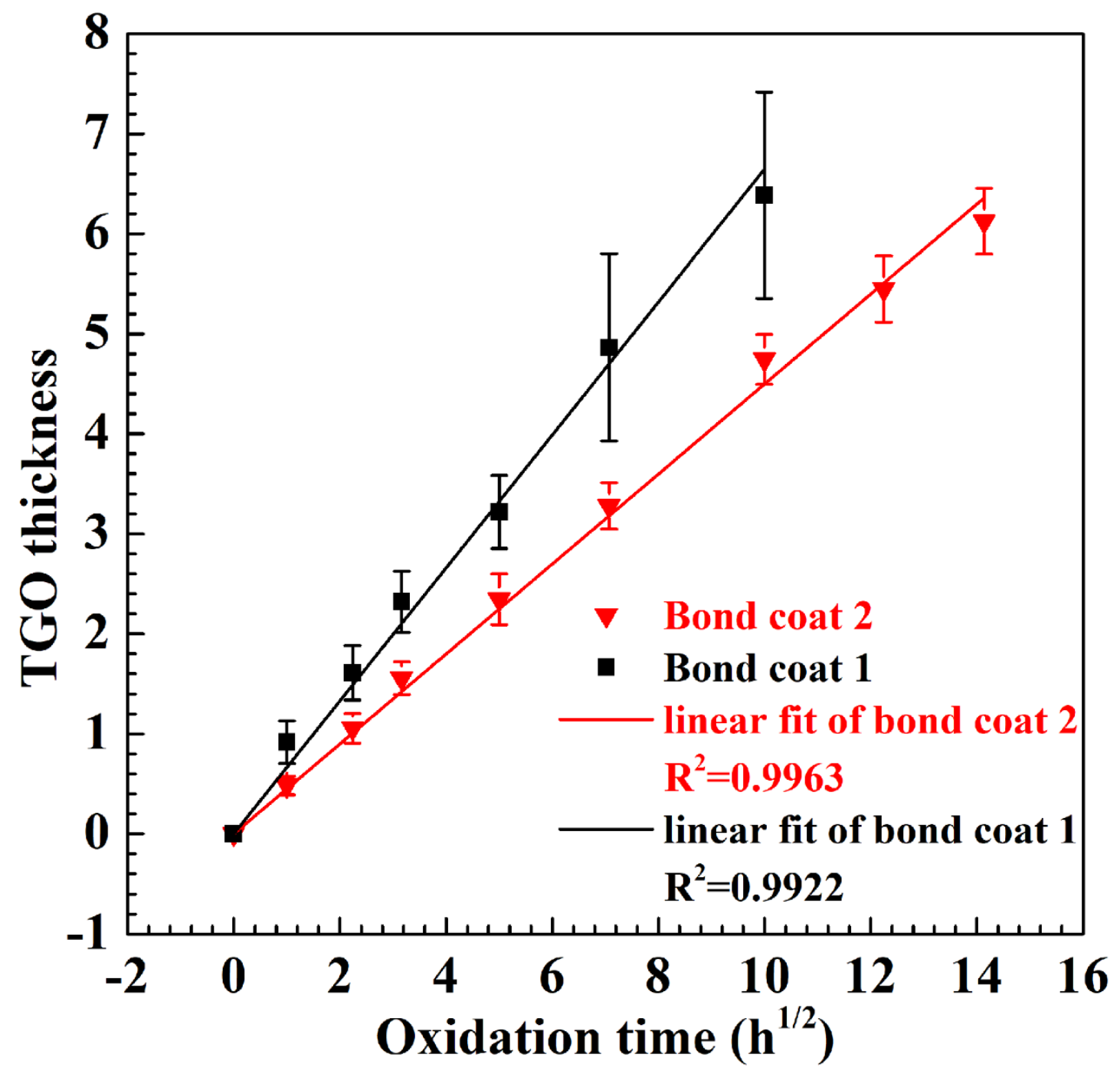

Fig .14. The average TGO thickness formed on the bond coats versus the square root of the oxidation time at $1150{ }^{\circ} \mathrm{C}$.

\subsection{S segregation measured by GD-OES}

The GD-OES technique is employed to examine the S segregation, which is a powerful tool for elemental depth profiling of multilayer material system [9, 33]. Fig. 15 shows the concentration-depth profiles of corresponding elements for bond coats after 50 hours oxidation. The sputtering depth at BC/TGO interface is basically consistent with the TGO thicknesses, which are presented in Fig. 14. It is clearly indicated that S segregation occurs both at $\mathrm{BC} / \mathrm{TGO}$ interface and in the inner layer of TGO in both bond coats. For the bond coat 1 , the concentration of $\mathrm{S}$ increases rapidly when sputtering depth approaches the interface. After exceeding the interface depth, the 
concentration of S slowly reduces with the increasing sputtering depth (Fig. 15a). These results indicates that $\mathrm{S}$ primarily segregates at the $\mathrm{BC} / \mathrm{TGO}$ interface for the bond coat 1. For the bond coat 2 , the concentration of $\mathrm{S}$ quickly declines from TGO surface to $\mathrm{BC} / \mathrm{TGO}$ interface, as presented in Fig. 15b. Thus the $\mathrm{S}$ segregation at BC/TGO interface is well inhibited for bond coat 2 . The reasons for the significant variation of $\mathrm{S}$ segregation at interface for two bond coats will be discussed later.
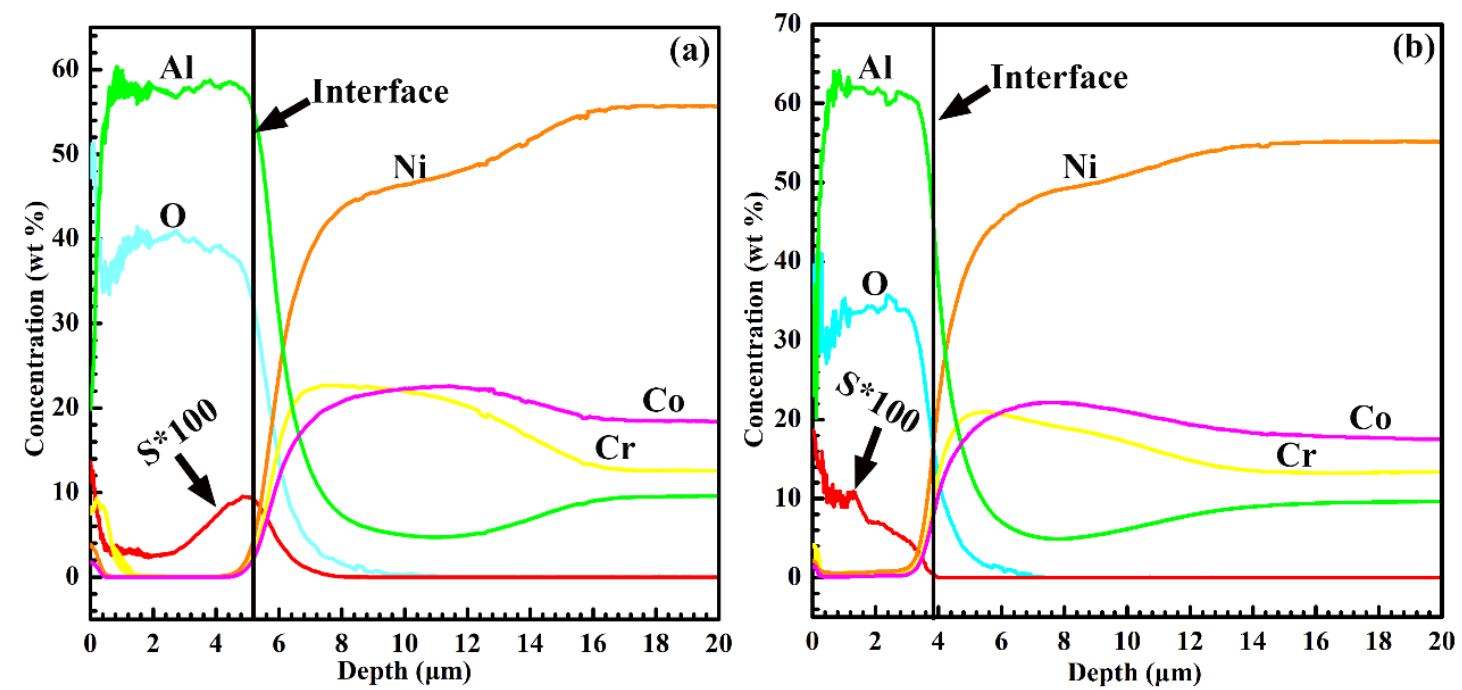

Fig. 15 The quantitative depth profiles of: (a) the bond coat 1 and (b) the bond coat 2 after isothermal oxidation at $1150^{\circ} \mathrm{C}$ for 50 hours. The depth profile of element $\mathrm{Y}$ is not showed in the graph, due to the lack of the certified calibration sample. Each element is listed with the corresponding scaling factor, e.g. S*100 means that the $\mathrm{S}$ concentration is 100 -times lower than what is displayed in the graph.

\section{Discussion}

It is clearly demonstrate that the bond coat 2 (powder milling) shows a lower oxidation rate, a better inhibiting effect of $\mathrm{S}$ segregation to $\mathrm{BC} / \mathrm{TGO}$ interface, and a much higher spallation life of TGO, as compared with the bond coat 1 . As reported in previous investigations $[22,30]$, the refinement of grain sizes to nanoscale will significantly affect the selective oxidation of alumina, which is induced by the significantly increased grain boundary density. Based on the results in Table 2, the grain size for the two types of bond coats is in the order of several micrometers. Therefore, the effect of grain size 
on the oxidation behavior can be neglected in the present work. According to the significant difference in TGO composition, TGO microstructure and interfacial morphologies for both bond coats (Fig. 11 and 12), the superior oxidation performance for the bond coat 2 is dependent on the uniform distribution of yttrium. Therefore, in the following, this work will devote to discuss the effect of uniformity of yttrium distribution on TGO growth rate, $\mathrm{S}$ segregation at interface and TGO spallation mechanism.

\subsection{The effect of the uniform distribution of yttrium on TGO growth rate}

For the bond coat 1, the large amount of Ni-Y enriched precipitates causes the largesized $\mathrm{Y}$-Al oxides incorporated into $\mathrm{Al}_{2} \mathrm{O}_{3}$-based TGO (Fig. 11 and 12). The Y-Al oxides and $\mathrm{Y}-\mathrm{Al}$ oxides $/ \mathrm{Al}_{2} \mathrm{O}_{3}$ interface will provide plenty of high diffusion paths for oxygen transport, which accelerates the TGO growth. Because the oxygen transports faster in $\mathrm{Y}-\mathrm{Al}$ oxides than in $\theta-\mathrm{Al}_{2} \mathrm{O}_{3}$ and $\alpha-\mathrm{Al}_{2} \mathrm{O}_{3}$ [11]. Additionally, the incorporation of large-sized Y-Al oxides will change the TGO growth mechanism, which can be indicated by the mixed structure of equiaxed grains and columnar grains in the TGO (Fig 12a). The mixed structure in the TGO on the bond coat 1 (Fig. 7a) suggests that the outward Al transport is facilitated, which contributes to an enhanced oxidation rate [9]. For the bond coat 2, the yttrium in the form of fine Ni-Y enriched precipitates and nano-sized $\mathrm{Y}_{2} \mathrm{O}_{3}$ particles, is uniformly distributed in the bond coat. Therefore, the bond coat 2 shows two different mechanisms of incorporation of Y-Al oxides into TGO. First, a part of $\mathrm{Y}-\mathrm{Al}$ oxides come from the diffusion of yttrium from the fine $\mathrm{Ni}-\mathrm{Y}$ enriched precipitates. Second, the remaining Y-Al oxides derive from the direct reaction of the nano-sized $\mathrm{Y}_{2} \mathrm{O}_{3}$ particles in contact with inwardly growing alumina-based TGO. Therefore, the fine, nano-sized $\mathrm{Y}-\mathrm{Al}$ oxides segregate to $\mathrm{Al}_{2} \mathrm{O}_{3}$ grain boundaries in the TGO (Fig. 7b-7e), which inhibits the outward Al transport and induces the formation of duplex microstructure in the TGO. These results result in a low oxidation rate for the bond coat 2 . 


\subsection{The effect of the uniform distribution of yttrium on $S$ impurity segregation}

In section 3.7, it is found by GD-OES that the $\mathrm{S}$ segregation at $\mathrm{BC} / \mathrm{TGO}$ interface is well inhibited after powder milling. For the bond coat 1 , the S primarily segregates to $\mathrm{BC} / \mathrm{TGO}$ interface. For the bond coat 2 , the $\mathrm{S}$ segregation occurs primarily in the inner layer of $\mathrm{TGO}$, rather than segregating at the $\mathrm{BC} / \mathrm{TGO}$ interface. Similar results are observed by Zhao et.al in the $\mathrm{Lu} / \mathrm{Hf}$ doped $\beta$-NiAl alloys [9]. The detailed mechanism of S segregation in the bond coats at high temperature remains under discussion [34]. As reported previously $[9,35]$, $\mathrm{S}$ preferentially segregates at $\mathrm{Al}_{2} \mathrm{O}_{3}$ grain boundaries and the surface of interface pores. As presented in Fig. 8, a considerable amount of interface pores are observed for bond coat 1 after 50 hours oxidation. The $\mathrm{S}$ will segregate to the surface of these pores, thereby promoting the growth of the pores at high temperature [9]. Recently, it is reported by Bai et.al[36] that the $\mathrm{S}$ in the form of sulfides(e.g. $\left.\mathrm{Al}_{2} \mathrm{~S}_{3}\right)$ can segregates to attached interface rather than segregating to the surface of interface pores, thereby leading to the degradation of interface adhesion. It has also been suggested by Toscano and Vaßen et.al [37] that TGO adhesion will degrade due to a low concentration of yttrium in the bond coat beneath a critical level. In other words, the rate of yttrium depletion from the bond coat is a crucial factor for maintaining the beneficial RE-effect. For the bond coat 1, the non-uniform distribution of yttrium (e.g. large-sized Ni-Y enriched precipitates) leads to a fast exhaustion of yttrium (beneath the critical level) due to yttrium incorporation into the TGO. Therefore, it is quite likely that a significant amount of $\mathrm{S}$ in the form of sulfides segregates to attached interface as result of inhomogeneity of yttrium distribution and fast exhaustion of yttrium in the bond coat 1 [36]. On the contrary, the uniform distribution of yttrium (e.g. fine Ni-Y enriched precipitates and nano-sized $\mathrm{Y}_{2} \mathrm{O}_{3}$ particles) in the bond coat 2 obtains the pores-free interface and slow exhaustion of yttrium from bond coat to TGO, which can decline the driving force of S segregation to interface. Thus the $\mathrm{S}$ segregation to interface in the bond coat 2 is well suppressed. 


\subsection{TGO spallation mechanisms}

It is extensively understood that delamination at the $\mathrm{BC} / \mathrm{TGO}$ interface occurs when the stored elastic strain energy $G$, exceeds the interfacial toughness $G_{c}$. The stored elastic strain energy in the TGO can be related to the residual stress in TGO, as [6]

$$
G=\frac{1-v_{\mathrm{ox}}^{2}}{2 E_{\mathrm{ox}}} \bar{\sigma}^{2} h_{o x}
$$

where $h_{o x}, v_{o x}$ and $\mathrm{E}_{\text {ox }}$ are the residual stress, thickness, Poisson' ratio and Young'

modulus of the TGO, respectively. $\bar{\sigma}$ is the residual stress in TGO which was evaluated using PLPS technique, by[9]

$$
\Delta v=5.07 \bar{\sigma}
$$

where $\Delta v$ is the peak shift of $\mathrm{R} 2$ line. The peak shift was obtained using the spalled TGO as stress free reference. The residual stress primarily comes from the growth stress and thermal expansion mismatch stress between the substrate and TGO.

Fig. 16a shows the evolution of residual stress in TGO as a function of oxidation time at $1150{ }^{\circ} \mathrm{C}$ for both bond coats. The residual stress are not recorded after 100 hours for the bond coat 1 due to the complete TGO failure. The initial rise in residual stress can be attributed to discontinuous nucleation and growth of TGO before 10 hours [38].The residual stress of TGO formed on two types of bond coats is substantially equal and remains a steady level $(\sim 4.9 \mathrm{GPa})$ after 10 hours. Thus the increase of totally elastic strain energy in TGO is primarily influenced by the TGO growth rate due to the substantially equal stress. As reported in the previous investigation [5], the tendency for delamination is directly link with the elastic strain energy in TGO. Thus the driving force for delamination increases linearly with TGO thickness, and hence parabolic increases with the oxidation time, $t$.

The BC/TGO interfacial toughness $G_{c}$ degrades with exposure time as result of $\mathrm{S}$ segregation to interface and imperfections grow (e.g. interface pores or oxide intrusions). As corroborated in Section 3.7 and Section 4.2, the S segregates rapidly to 
interface for the bond coat 1 , which contributes to an initial rapid decrease in interfacial toughness. Then the slower decay in the interfacial toughness is induced by interfacial imperfections. For the bond coat 2, the slower decrease in interfacial toughness is legitimately expected, due to effectively inhibiting effect of S segregation to interface (Fig. 15) and imperfections grow (Fig. 10). The interfacial toughness and driving force for TGO delamination for both bond coats, as a function of oxidation time are presented in Fig. 16b. The intersection of the driving force for delamination curve with the interfacial toughness curve represents the time to failure of the TGO. As shown in Fig. $17 \mathrm{~b}$, the higher interfacial toughness and lower driving force for delamination result in the higher spallation life of TGO for bond coat 2.

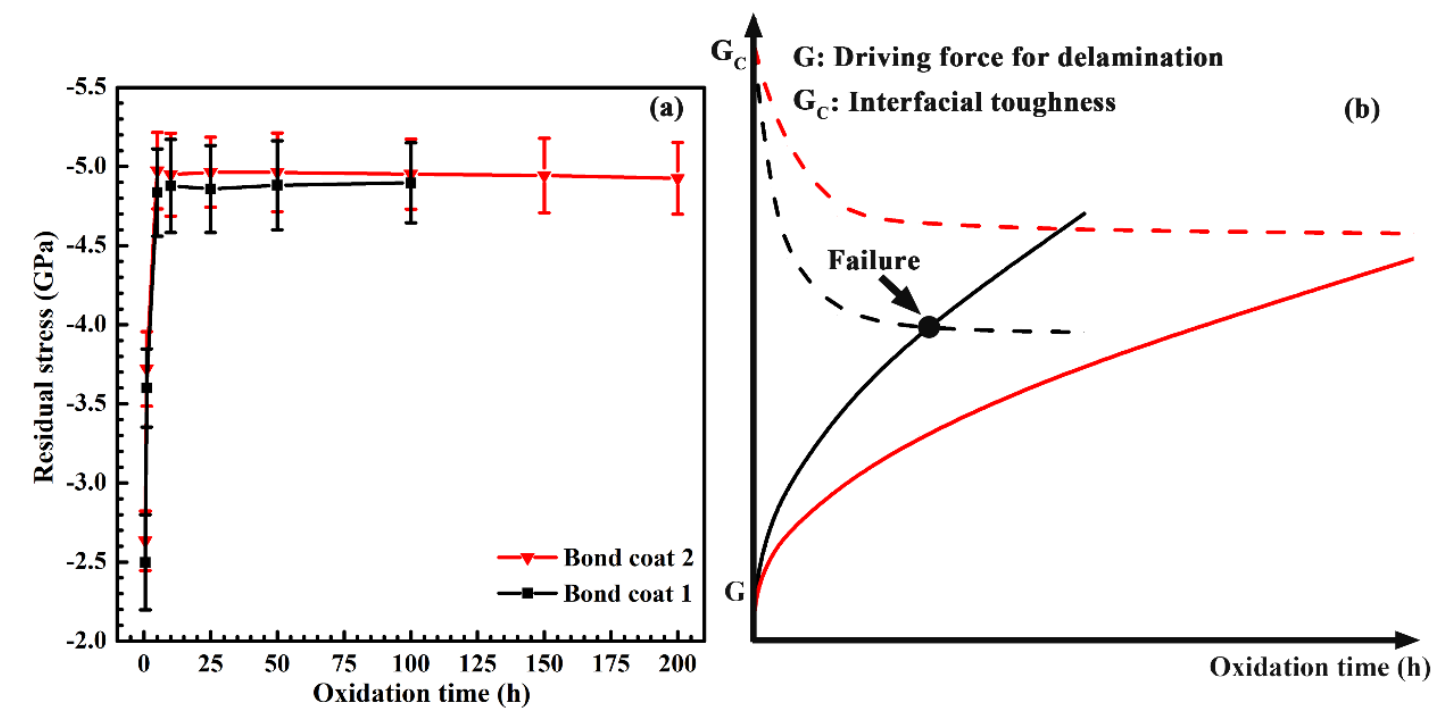

Fig. 16 (a) the residual stress of TGO as a function of oxidation time at $1150{ }^{\circ} \mathrm{C}$, (b) schematic representation of driving force for delamination (solid lines) and interfacial toughness (dash lines) at the BC/TGO interface, as a function of thermal exposure time. The black lines represent the bond coat 1 and red lines represent the bond coat 2 .

On the other hand, TGO suffers severe spallation ( 20\%) after 50 hours oxidation for the bond coat 1, when the TGO thickness reaches $\sim 5 \mu \mathrm{m}$ (Fig. 9 and 10). However, when TGO thickness exceeds $6 \mu \mathrm{m}$ after 200 hours oxidation for the bond coat 2, only about a $0.4 \%$ spallation of TGO occurs (Fig. 9 and 10). In other words, higher driving force for delamination (higher TGO thickness) do not lead to higher TGO spallation degree for bond coat 2 . This result clearly indicates that the high interfacial toughness for the bond coat 2 plays a predominant role in high TGO spallation life, as compared 
with the low oxidation rate.

\section{Conclusions}

The highly oxidation and spallation resistant NiCoCrAlY bond coat fabricated by SPS using the milled powder was presented in this work. The oxidation rate of bond coat 2 is significantly reduced after powder milling, with the parabolic growth rate constant reduced by $55 \%$, compared with the bond coat 1 . The isothermal oxidation tests at $1150{ }^{\circ} \mathrm{C}$ demonstrate that the bond coat 2 shows much better spallation resistance. The spallation degree of TGO on the bond coat 1 is approximately $20 \%$ after 50 hours oxidation and exceeds $90 \%$ after 100 hours oxidation. However, the TGO on the bond coat 2 is almost intact and only about $0.4 \%$ TGO spallation even after 200 hours oxidation.

For the bond coat 1, the yttrium in the form of large-sized Ni-Y enriched precipitates $(300 \sim 700 \mathrm{~nm})$ segregates at grain boundaries. On the contrary, the yttrium in the form of fine Ni-Y enriched precipitates $(50 \sim 150 \mathrm{~nm})$ and nano-sized $\mathrm{Y}_{2} \mathrm{O}_{3}$ particles $(5 \sim 30$ $\mathrm{nm}$ ) is uniformly distributed in the bond coat 1 after powder milling. This uniform distribution of yttrium can contribute to the segregation of nano-sized YAP at $\mathrm{Al}_{2} \mathrm{O}_{3}$ grain boundaries in TGO, which leads to a lower oxidation rate.

For the bond coat $1, \mathrm{~S}$ primarily segregates at the BC/TGO interface, probably due to the non-uniform distribution of Ni-Y enriched precipitates and fast consumption of yttrium at high temperature. However, for the bond coat 2, S segregation at BC/TGO interface is well suppressed, which could be attributed to the uniform distribution of yttrium in the bond coat. Furthermore, the $\mathrm{S}$ is primarily detected in the inner layer of TGO.

The interfacial imperfections (e.g. pores and oxide intrusions) are found at BC/TGO interface for the bond coat 1 . After powder milling, the formation of interfacial imperfections are suppressed for bond coat 2, which results from the uniform distribution of yttrium.

In short, the beneficial RE-effect is obtained for a given yttrium content, only when the 
yttrium is uniformly distributed in the bond coat. For bond coat 2, the effectively inhibiting effect of S segregation to interface and formation of interfacial imperfections leads to an improved interfacial adhesion. The low TGO growth rate results in low driving force for interface delamination. Eventually, these results contribute to the high spallation lifetime of TGO. Additionally, improving the interface adhesion is more useful than lowering the oxidation rate for enhancing the TGO spallation resistance in the present study.

\section{Acknowledgements}

This work was supported by the Inner Mongolia Natural Science Foundation (No. 2017MS0538) and Baotou-SJTU innovation funding.

\section{References}

[1] A.G. Evans, D.R. Mumm, J.W. Hutchinson, G.H. Meier, F.S. Pettit, Mechanisms controlling the durability of thermal barrier coatings, Prog. Mater. Sci. 46(5) (2001) $505-553$.

[2] N.P. Padture, M. Gell, E.H. Jordan, Thermal barrier coatings for gas-turbine engine applications, Science 296 (5566) (2002) 280-4.

[3] D.R. Mumm, A.G. Evans, On the role of imperfections in the failure of a thermal barrier coating made by electron beam deposition, Acta Mater. 48(8) (2000) 1815-1827. [4] F. Cao, B. Tryon, C.J. Torbet, T.M. Pollock, Microstructural evolution and failure characteristics of a NiCoCrAlY bond coat in "hot spot" cyclic oxidation, Acta Mater. 57(13) (2009) 3885-3894.

[5] R.W. Jackson, D.M. Lipkin, T.M. Pollock, Thermal barrier coating adherence to Hfmodified B2 NiAl bond coatings, Acta Mater. 80 (2014) 39-47.

[6] L. Luo, X. Shan, Z. Zou, C. Zhao, X. Wang, A. Zhang, X. Zhao, F. Guo, P. Xiao, A high performance NiCoCrAlY bond coat manufactured using laser powder deposition, Corros. Sci. 126 (2017) 356-365.

[7] A. Gil, D. Naumenko, R. Vassen, J. Toscano, M. Subanovic, L. Singheiser, W.J. 
Quadakkers, Y-rich oxide distribution in plasma sprayed MCrAlY-coatings studied by SEM with a cathodoluminescence detector and Raman spectroscopy, Surf. Coat. Technol. 204(4) (2009) 531-538.

[8] E. Hejrani, D. Sebold, W.J. Nowak, G. Mauer, D. Naumenko, R. Vaßen, W.J. Quadakkers, Isothermal and cyclic oxidation behavior of free standing MCrAlY coatings manufactured by high-velocity atmospheric plasma spraying, Surf. Coat. Technol. 313 (2017) 191-201.

[9] C. Zhao, Y. Zhou, Z. Zou, L. Luo, X. Zhao, F. Guo, P. Xiao, Effect of alloyed Lu, $\mathrm{Hf}$ and $\mathrm{Cr}$ on the oxidation and spallation behavior of NiAl, Corros. Sci. 126 (2017) 334-343.

[10] T.J. Nijdam, W.G. Sloof, Effect of reactive element oxide inclusions on the growth kinetics of protective oxide scales, Acta Mater. 55(17) (2007) 5980-5987.

[11] T.J. Nijdam, L.P.H. Jeurgens, J.H. Chen, W.G. Sloof, On the Microstructure of the Initial Oxide Grown by Controlled Annealing and Oxidation on a NiCoCrAlY Bond Coating, Oxid. Met. 64(5-6) (2005) 355-377.

[12] G. Mauer, D. Sebold, R. Vaßen, E. Hejrani, D. Naumenko, W.J. Quadakkers, Impact of processing conditions and feedstock characteristics on thermally sprayed MCrAlY bondcoat properties, Surf. Coat. Technol. 318 (2017) 114-121.

[13] N.M. Yanar, G.H. Meier, F.S. Pettit, The influence of platinum on the failure of EBPVD YSZ TBCs on NiCoCrAlY bond coats, Scr. Mater. 46(4) (2002) 325-330.

[14] T.J. Nijdam, W.G. Sloof, Effect of Y Distribution on the Oxidation Kinetics of NiCoCrAlY Bond Coat Alloys, Oxid. Met. 69(1-2) (2007) 1-12.

[15] J. Song, K. Ma, L. Zhang, J.M. Schoenung, Simultaneous synthesis by spark plasma sintering of a thermal barrier coating system with a NiCrAlY bond coat, Surf. Coat. Technol. 205(5) (2010) 1241-1244.

[16] D. Monceau, D. Oquab, C. Estournes, M. Boidot, S. Selezneff, Y. Thebault, Y. Cadoret, Pt-modified Ni aluminides, MCrAlY-base multilayer coatings and TBC systems fabricated by Spark Plasma Sintering for the protection of Ni-base superalloys, Surf. Coat. Technol. 204(6-7) (2009) 771-778.

[17] P. Audigié, S. Selezneff, A. Rouaix-Vande Put, C. Estournès, S. Hamadi, D. 
Monceau, Cyclic Oxidation Behavior of TBC Systems with a Pt-Rich $\gamma-\mathrm{Ni}+\gamma^{\prime}-\mathrm{Ni}_{3} \mathrm{Al}$ Bond-Coating Made by SPS, Oxid. Met. 81(1-2) (2013) 33-45.

[18] F. Nozahic, C. Estournès, A.L. Carabat, W.G. Sloof, S. van der Zwaag, D. Monceau, Self-healing thermal barrier coating systems fabricated by spark plasma sintering, Mater. Des. 143 (2018) 204-213.

[19] A.H. Pakseresht, A.H. Javadi, M. Bahrami, F. Khodabakhshi, A. Simchi, Spark plasma sintering of a multilayer thermal barrier coating on Inconel 738 superalloy: Microstructural development and hot corrosion behavior, Ceram. Int. 42(2) (2016) 2770-2779.

[20] J. Kulczyk-Malecka, X. Zhang, J. Carr, F. Nozahic, C. Estournès, D. Monceau, A.L. Carabat, W.G. Sloof, S. van der Zwaag, P.J. Withers, P. Xiao, Thermo mechanical properties of SPS produced self-healing thermal barrier coatings containing pure and alloyed MoSi 2 particles, J. Eur. Ceram. Soc. 38(12) (2018) 4268-4275.

[21] D. Mercier, B.D. Gauntt, M. Brochu, Thermal stability and oxidation behavior of nanostructured NiCoCrAlY coatings, Surf. Coat. Technol. 205(17-18) (2011) $4162-$ 4168.

[22] Q. Zhang, C.-J. Li, C.-X. Li, G.-J. Yang, S.-C. Lui, Study of oxidation behavior of nanostructured NiCrAlY bond coatings deposited by cold spraying, Surf. Coat. Technol. 202(14) (2008) 3378-3384.

[23] M. Tahari, M. shamanian, M. salehi, The effect of heat treatment and thermal spray processes on the grain growth of nanostructured composite CoNiCrAlY/YSZ powders, J. Alloys Compd. 646 (2015) 372-379.

[24] R.V. J. Toscano, A. Gil, M. Subanovic, D. Naumenko, L. Singheiser, W.J., Quadakkers, Parameters affecting TGO growth and adherence on MCrAlY-bond coats for TBC's, Surf. Coat. Technol (2006) 3906-3910.

[25] L. Ajdelsztajn, D. Hulbert, A. Mukherjee, J.M. Schoenung, Creep deformation mechanism of cryomilled NiCrAlY bond coat material, Surf. Coat. Technol. 201(24) (2007) 9462-9467.

[26] Z. Fu, W. Chen, H. Wen, D. Zhang, Z. Chen, B. Zheng, Y. Zhou, E.J. Lavernia, Microstructure and strengthening mechanisms in an FCC structured single-phase 
nanocrystalline Co $25 \mathrm{Ni} 25 \mathrm{Fe} 25 \mathrm{Al} 7.5 \mathrm{Cu} 17.5$ high-entropy alloy, Acta Mater. 107 (2016) 59-71.

[27] S. Fang, W. Chen, Z. Fu, Microstructure and mechanical properties of twinned $\mathrm{A} 10.5 \mathrm{CrFeNiCo} 0.3 \mathrm{C} 0.2$ high entropy alloy processed by mechanical alloying and spark plasma sintering, Mater. Des. (1980-2015) 54 (2014) 973-979.

[28] Y.H. Sohn, J.H. Kim, E.H. Jordan, M. Gell, Thermal cycling of EB-PVD/MCrAlY thermal barrier coatings: I. Microstructural development and spallation mechanisms, Surf. Coat. Technol. 146-147 (2001) 70-78.

[29] W. Braue, P. Mechnich, K. Fritscher, L. Niewolak, Compatibility of mixed zone constituents (YAG, YAP, YCrO3) with a chromia-enriched TGO phase during the late stage of TBC lifetime, Surf. Coat. Technol. 202(4-7) (2007) 670-675.

[30] Y. Chen, X. Zhao, P. Xiao, Effect of microstructure on early oxidation of MCrAlY coatings, Acta Mater. 159 (2018) 150-162.

[31] S.-S. Kim, Y.-F. Liu, Y. Kagawa, Evaluation of interfacial mechanical properties under shear loading in EB-PVD TBCs by the pushout method, Acta Mater. 55(11) (2007) 3771-3781.

[32] H. Peng, H. Guo, J. He, S. Gong, Microscale lamellar NiCoCrAlY coating with improved oxidation resistance, Surf. Coat. Technol. 207 (2012) 110-116.

[33] Z. Wěiss, K. Marshall, Elemental depth profiling of coated and surface-modified materials by GD-OES: hard coatings on cutting tools, Thin Solid Films 308-309 (1997) $382-388$.

[34] D. Naumenko, B.A. Pint, W.J. Quadakkers, Current Thoughts on Reactive Element Effects in Alumina-Forming Systems: In Memory of John Stringer, Oxid. Met. 86(1-2) (2016) 1-43.

[35] R. Molins, I. Rouzou, P. Hou, A TEM study of sulfur distribution in oxidized Ni40Al and its effect on oxide growth and adherence, Mater. Sci. Eng. A. 454-455 (2007) 80-88.

[36] M. Bai, H. Jiang, Y. Chen, Y. Chen, C. Grovenor, X. Zhao, P. Xiao, Migration of sulphur in thermal barrier coatings during heat treatment, Mater. Des. 97 (2016) 364371. 
[37] J. Toscano, R. Vaßen, A. Gil, M. Subanovic, D. Naumenko, L. Singheiser, W.J. Quadakkers, Parameters affecting TGO growth and adherence on MCrAlY-bond coats for TBC's, Surf. Coat. Technol. 201(7) (2006) 3906-3910.

[38] J. Liu, J.W. Byeon, Y.H. Sohn, Effects of phase constituents/microstructure of thermally grown oxide on the failure of EB-PVD thermal barrier coating with NiCoCrAlY bond coat, Surf. Coat. Technol. 200(20-21) (2006) 5869-5876. 